\title{
Adolescent Girls Initiative-Kenya: Qualitative report
}

\author{
Eunice N. Muthengi \\ Population Council \\ Karen Austrian \\ Population Council \\ Amanda Landrian \\ Benta Abuya \\ Joyce Mumah
}

See next page for additional authors

Follow this and additional works at: https://knowledgecommons.popcouncil.org/departments_sbsr-pgy

Part of the Demography, Population, and Ecology Commons, Family, Life Course, and Society Commons, International Public Health Commons, and the Women's Health Commons How does access to this work benefit you? Let us know!

\section{Recommended Citation}

Muthengi, Eunice N., Karen Austrian, Amanda Landrian, Benta Abuya, Joyce Mumah, and Caroline W. Kabiru. 2016. "Adolescent Girls Initiative-Kenya: Qualitative report." Nairobi: Population Council. 


\section{Authors}

Eunice N. Muthengi, Karen Austrian, Amanda Landrian, Benta Abuya, Joyce Mumah, and Caroline W. Kabiru 


\section{ADOLESCENT GIRLS INITIATIVE-KENYA QUALITATIVE REPORT}

Eunice Muthengi, PhD Karen Austrian, PhD Amanda Landrian, BS Benta A. Abuya, PhD Joyce Mumah, PhD Caroline W. Kabiru, PhD 
Ideas. Evidence. Impact.

The Population Council confronts critical health and development issues-from stopping the spread of HIV to improving reproductive health and ensuring that young people lead full and productive lives. Through biomedical, social science, and public health research in 50 countries, we work with our partners to deliver solutions that lead to more effective policies, programs, and technologies that improve lives around the world. Established in 1952 and headquartered in New York, the Council is a nongovernmental, nonprofit organization governed by an international board of trustees.

Population Council

General Accident House

Ralph Bunche Road

PO Box 17643-00500

Nairobi, Kenya

Tel: +254202713480

Tel2: +254202713481

Fax: +254202713479

www.popcouncil.org

\author{
AUTHORS \\ Eunice Muthengi, PhD \\ AGI-K Deputy Team Leader \\ Associate \\ Population Council, Kenya \\ Karen Austrian, PhD \\ AGI-K Team Leader \\ Associate \\ Population Council, Kenya \\ kaustrian@popcouncil.org \\ Amanda Landrian \\ MPH Candidate, University of California, \\ Los Angeles \\ Graduate Intern \\ Population Council, Kenya
}

Suggested citation: Muthengi, E., K. Austrian, A. Landrian, B.A. Abuya, J. Mumah, and C.W. Kabiru. 2016. “Adolescent Girls Initiative-Kenya Qualitative Report.” Nairobi: Population Council. 


\section{Table of Contents}

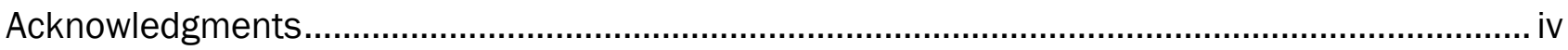

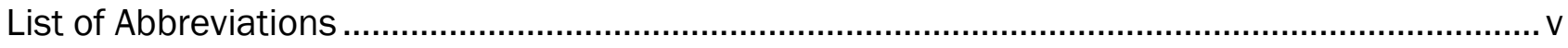

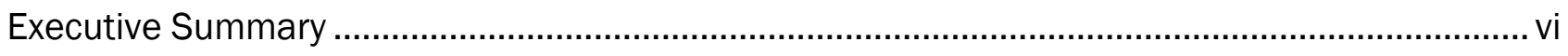

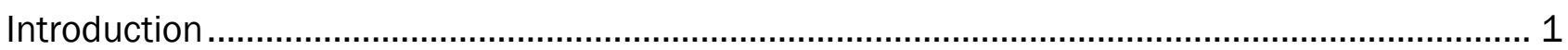

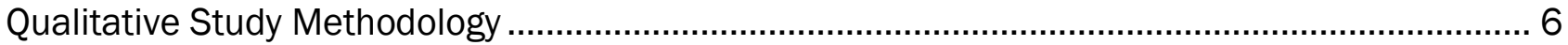

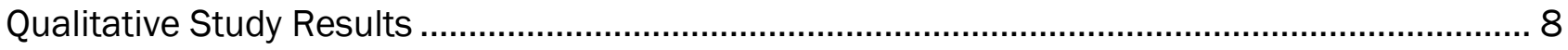

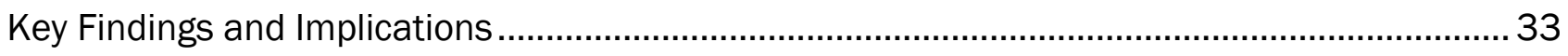

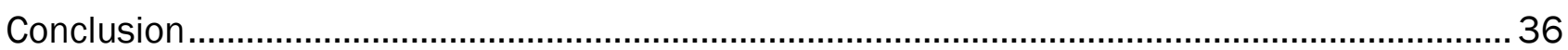

Appendix A

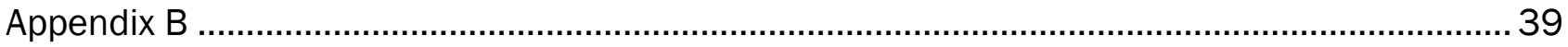

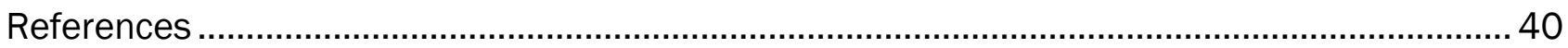




\section{Acknowledgments}

The AGI-K Qualitative Report would not be possible without the hard work of the project partners and research teams dedicated to improving the lives of vulnerable adolescent girls. AGI-K is implemented by a consortium led by the Population Council, with the African Population and Health Research Center (APHRC) as research partner, Save the Children as implementing partner in Wajir, Plan International as implementing partner in the Nairobi slums, and Itad as a consultant on the cost-effectiveness analysis. We thank all the project members, the members of the AGI-K National External Advisory Committee (EAC), and the Kibera and Wajir EACs for their invaluable input into the intervention and research design (see Appendix A).

We would like to acknowledge Eva Muluve and Faith Mbushi-Njagah, both based in the Population Council office in Kenya, for their efforts in coordinating the qualitative data collection. We also thank the Population Council's AGI-K Program Coordinator, Diana Moreka, and our implementing partners, Save the Children and Plan International, especially Program Managers Wakarura Kimani and Joy Koech, for their overall management and oversight of intervention activities. We would also like to recognize Laura Muthoni for her invaluable contributions in the qualitative data analysis phase.

We thank the UK Department for International Development (DFID) for investing in rigorous research that will provide evidence to influence national policy and will support scaled-up, cost-effective interventions for adolescent girls in the future. We also thank those from DFID-Kenya and the AGI-K Expert Research Committee who provided feedback on the research design and on drafts of this report.

Finally, we are grateful to the adolescent girls, their parents/guardians, mentors, community conversations facilitators, and community gatekeepers who participated in the research and took the time to share their thoughts and experiences with us. 


\section{List of Abbreviations}

$\begin{array}{ll}\text { AGI-K } & \text { Adolescent Girls Initiative-Kenya } \\ \text { APHRC } & \text { African Population and Health Research Center } \\ \text { CAT } & \text { Coding Analysis Toolkit } \\ \text { CC } & \text { Community Conversations } \\ \text { CCT } & \text { Conditional Cash Transfer } \\ \text { CSE } & \text { Comprehensive Sexuality Education } \\ \text { DFID } & \text { UK Department for International Development } \\ \text { EAC } & \text { External Advisory Committee } \\ \text { ERC } & \text { Expert Research Committee } \\ \text { FGD } & \text { Focus Group Discussion } \\ \text { FGM/C } & \text { Female Genital Mutilation/Cutting } \\ \text { HCT } & \text { Household Cash Transfer } \\ \text { ICR } & \text { Inter-coder Reliability } \\ \text { IDI } & \text { In-depth Interview } \\ \text { KES } & \text { Kenya Shillings } \\ \text { QDAP } & \text { Qualitative Data Analysis Program } \\ \text { RCT } & \text { Randomized Controlled Trial } \\ \text { STI } & \text { Sexually Transmitted Infection } \\ \text { UNDP } & \text { United Nations Development Programme }\end{array}$




\section{Executive Summary}

Adolescent girls in Kenya face a number of risks and vulnerabilities that can affect their health, education status, and general well-being. The Adolescent Girls Initiative-Kenya (AGI-K) is currently delivering multi-sectoral interventions, targeting violence prevention, education, health, and wealth creation, to adolescent girls aged 1114 in two marginalized areas of Kenya: 1) the urban slums of Kibera in Nairobi, and 2) Wajir County in Northeastern Kenya. A randomized controlled trial (RCT) design is being used to compare the impact of four different intervention packages, along with their associated costs, to assess if and how intervening in early adolescence will impact girls' lives as they transition into early adulthood. This report provides a brief overview of the research design and intervention components being delivered in AGI-K, and presents findings from the first round of qualitative data collection intended to highlight the strengths and weaknesses of the implementation processes thus far.

\section{KEY FINDINGS}

\section{Education Support Program}

Most program beneficiaries from both study sites reported satisfaction with the education intervention, which included the schooling kit, having school fees paid, and receiving the household cash transfer (HCT). Benefits described included decreased financial burden, improvements in school attendance and enrollment, and increased self-esteem and confidence among enrolled adolescent girls. However, despite repeated community sensitization efforts in both study locations, study findings also highlighted remaining misconceptions and concerns about the education support program. For example, in both Kibera and Wajir, many beneficiaries were unaware that the program only pays a fraction of the girls' total school fees and that parents may still be responsible for additional payments.

\section{Safe Spaces}

Qualitative findings highlight the perceived positive effects of the Safe Spaces meetings on the girls from both the parents' and girls' perspective. In Wajir, results provide early evidence for changes in attitudes toward early marriage, while in Kibera, the findings indicate increased social assets, such as aspiration and self-esteem. For girls receiving the wealth creation intervention, there was a notable increase in their savings activities and financial responsibility. Adolescents from both study sites reported forming important friendships with other girls in their Safe Spaces group, thus expanding their peer networks. Mentors also discussed the perceived benefits from the program, reporting increased knowledge, self-esteem, confidence, and capacity. In both Kibera and Wajir, mentors have been able to forge important relationships with girls and parents alike, as they described their experiences with girls and parents coming to them when seeking guidance, help, and assistance.

Parents and adolescents in Kibera described a general satisfaction with the knowledge being gained from topics covered during the sessions, particularly those revolving around menstrual hygiene and management, sexual and reproductive health, and money management. Although parents and gatekeepers in Wajir reported satisfaction with many components of the curriculum, the research findings also highlight several misconceptions and concerns that still exist regarding some of the topics covered within the sexual and reproductive health curriculum, such as family planning and early marriage.

\section{Violence Prevention through Community Conversations}

At the time of data collection, the Community Conversations (CC) groups had been successfully formed in Wajir but were not yet active. As a result, information on the progression of CC meetings could only be obtained from Kibera respondents.

In general, CC facilitators noted satisfaction with the meetings and commented that being a CC facilitator had already had a positive effect on them as individuals. In their role as facilitators, they have been empowered to become strong leaders and role models within their communities, evidenced by how community members seek their help and guidance in solving problems and resolving personal conflicts. Although facilitators and committee members discussed several areas of satisfaction with the progression of meetings, they also discussed reasons why community members may not attend meetings, including poor communication about meeting details, and they expressed concern about the attendees being only those who are directly benefitting from the program. 


\section{Introduction}

Adolescent girls in Kenya and other countries in sub-Saharan Africa face considerable vulnerabilities including household poverty, violence, limited educational opportunities, and a lack of economic opportunities and independence. ${ }^{1}$ These vulnerabilities can have a significant impact on their health, education, and socioeconomic status throughout the lifespan, as they increase the risk of experiencing negative outcomes such as school dropout, early sexual initiation, unintended pregnancy, and early marriage. For the most part, girls in early adolescence living in environments laden with these vulnerabilities have not yet experienced these associated negative events, providing a critical window of opportunity to intervene before they experience these potentially irreversible outcomes. ${ }^{2}$

The Adolescent Girls Initiative-Kenya (AGI-K) is a randomized controlled trial (RCT) designed to test whether a combination of interventions, targeted to young adolescent girls aged 11-14, can improve their well-being and enable a safe and productive transition into adulthood. The two-year interventions are being delivered in two different marginalized areas of Kenya-the Kibera slums in the capital city of Nairobi, and rural Wajir County located near the Kenya-Somali border-and comprises a combination of girl-level, household-level, and communitylevel interventions.

Kibera is characterized by an ethnically and religiously diverse population with high levels of household poverty and crime and a lack of formal basic services. ${ }^{3}$ On the other hand, Wajir County is a sparsely populated rural area made up of an ethnically (Somali) and religiously (Muslim) homogenous population with some of the poorest health, education, and socioeconomic indicators in the country. ${ }^{1,4}$ In addition, findings from the AGI-K baseline survey found that adolescent girls from Kibera and Wajir County differed greatly in terms of their specific education, wealth creation, health, and violence experience, providing further justification for the inclusion of both study sites in the trial. ${ }^{4}$

The AGI-K program design and methods have been previously published in detail.5,6 Thus, this report will provide only a brief overview of the research design and methods of AGI-K, and instead focus on presenting findings from qualitative interviews with beneficiaries of the program and others who are involved in study intervention implementation. These findings provide important insight into the benefits and challenges associated with the AGI$\mathrm{K}$ program. From these insights, recommendations are made in order to improve upon study implementation processes as the project continues.

\section{RANDOMIZED CONTROLLED TRIAL DESIGN}

The AGI-K research design was developed and refined based on findings from needs assessments conducted by the implementing partners (Plan International in Kibera and Save the Children in Wajir) in the two settings, discussions, and workshops with study investigators, consultations with the External Advisory Committee (EAC), a and feedback from the Expert Research Committee $(E R C)^{b}$ and the UK Department for International Development (DFID).

Because of the vast differences in culture, context, and baseline characteristics of key indicators in Nairobi versus Wajir, AGI-K comprises two sub-studies with independent datasets for each of the two project locations. Although the intervention packages being delivered in each site are similar, the components include slight variations that reflect local social and cultural norms. The advantage of this approach is that findings from each of the substudies can be compared-conclusions can be drawn on whether the same package of interventions had the greatest impact on the outcomes of interest and it will be possible to explore what differences may exist and why.

Although a randomized approach was used in both project sites, the unit of randomization differs. An individuallevel randomization approach was possible in the urban setting of Nairobi, whereas in Wajir, cluster-level randomization was more suitable. A non-experimental external control is also included in the design of the Nairobi sub-study, allowing for a comparison with a similar area that did not receive any of the four intervention packages. By including this external control, researchers will be able to use quasi-experimental methodologies to examine

\footnotetext{
a The External Advisory Committee is a Population Council-convened group that advises on general project strategy and research uptake. It is comprised of government, civil society, and multi-lateral representatives.

${ }^{\mathrm{b}}$ The Expert Research Committee is a DFID-convened group that provides guidance for the project and quality assurance. It is comprised of DFID research staff and two external consultants who are experts in impact evaluation.
} 
the impact of the violence prevention-only arm, identify the additional effect of including each additional component, and identify those impacts attributable to each intervention package as a whole. Because community leaders indicated that it would be socially unacceptable to conduct research without providing a direct benefit to participants, an external control could not be included in the Wajir sub-study. As a result, it will not be possible to assess the potential impact of the violence prevention-only arm in Wajir.

\section{STUDY OBJECTIVES}

AGI-K is testing combinations of multi-sectoral interventions to answer the following questions: a) What combination(s) of interventions produce(s) the greatest positive impact in the well-being of adolescent girls; and b) What is the most cost-effective way to achieve the greatest impact for adolescent girls?

The primary objective of AGI-K is to improve the well-being of beneficiary girls after four years, delaying childbearing and enabling a safe and productive transition into adulthood (see Appendix B). ${ }^{c}$ While a number of outcomes related to this comprehensive objective are specified, there is no single indicator that fully captures it. The study is powered to detect differences in mean number of years of schooling completed and the proportion of girls who have ever been pregnant. However, evidence will be drawn from a combination of relevant primary and secondary outcome indicators that span all four domains of the interventions being implemented.

The specific objectives of this first-round qualitative study are to better understand beneficiaries' experiences, any perceived effects of the program on the individual girl, the intervention strengths and weaknesses, and the improvements that can be made to intervention implementation processes to increase uptake and participation. This qualitative data is intended to compliment the quantitative data being collected throughout the study duration.

\section{THEORY OF CHANGE}

The interventions being delivered in AGI-K were based on the Asset Building Theory of Change that posits that girls need a combination of education, social, health, and economic assets in order to make safe, healthy, and productive transitions into adulthood. 7,8 The hypothesis is that this asset-building will lead to increased educational attainment, delayed marriage and childbearing, fewer unintended pregnancies, decreased experience of violence, and improvements in income generation and financial independence (see Figure 1).

FIGURE 1. AGI-K Theory of Change

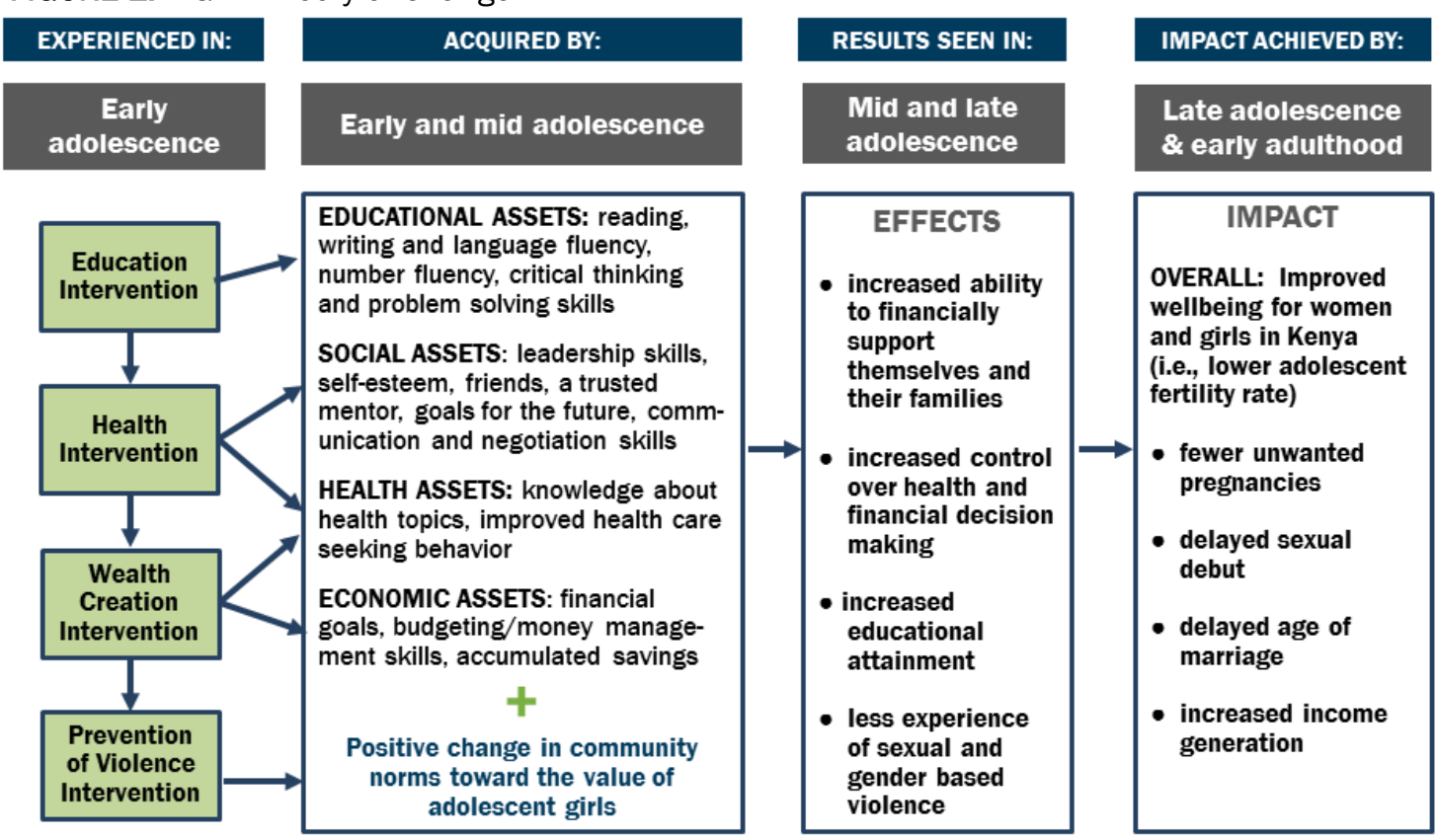

\footnotetext{
${ }^{c}$ Appendix B describes the causal mechanisms by which interventions may affect the timing of childbearing.
} 


\section{INTERVENTIONS}

As described above, the aim of AGI-K is to test multi-sectoral packages of interventions. Girls from both study sites will be randomized to one of the following intervention packages:

1) Violence Prevention Only (V-only)

2) Violence Prevention + Education (VE)

3) Violence Prevention + Education + Health (VEH)

4) Violence Prevention + Education + Health + Wealth Creation (VEHW)

Conceptual and logistical considerations drove the selection of the specific combinations of interventions to be compared across the four arms of the study, and included: 1) prioritizing what component effects were important to isolate; 2) generating evidence on new intervention combinations for which currently there are none; and 3 ) testing packages with varying associated costs.

Descriptions for each of the four sector-specific interventions are provided below.

\section{Violence Prevention}

Within the context of AGI-K, the definition of violence incorporates a broader conceptualization including physical and sexual violence, along with other activities that lead to the devaluation of girls, including lack of education, early marriage, and female genital mutilation/cutting (FGM/C). In order to prevent violence against girls, the program has implemented a community-level intervention based on the Concern International/United Nations Development Programme (UNDP) Community Conversations (CC) model. Through regularly scheduled CC meetings, several members of the community are able to engage in dialogue aimed at identifying problems that inhibit gender norms or attitudes and design their own context-specific solutions to these problems. In this way, the community is able to build self-efficacy and a sense of ownership in addressing social issues.

To implement the $\mathrm{CC}$ model, the implementing partners facilitated the establishment of a core committee within each village comprised of religious and community leaders, parents, teachers, and young men and women. A CC facilitator was also appointed to each committee and tasked with following a prescribed manual with specific topics, activities, and tools. These materials are meant to facilitate discussions that aid the committees in identifying the key drivers of violence against girls within their communities, develop a written "contract" that includes specific steps to combat those determinants, and then carry out those specific activities outlined in their contract over the course of the two-year intervention period. To help the communities in fulfilling their contracts, up to 200,000 Kenyan Shillings (KES) (approximately US $\$ 2,000^{d}$ ) worth of in-kind materials and services have been made available to each $\mathrm{CC}$ group. The $\mathrm{CC}$ meeting activities, including implementation of contracts, are being monitored by the respective implementing partner.

\section{Education}

All girls in the relevant study arms were eligible for enrollment in the AGI-K education intervention irrespective of their baseline schooling status (i.e., whether or not they were currently enrolled in school). The intervention comprises a conditional cash transfer (CCT) based on at least $80 \%$ attendance for each school term over the course of the two-year program, with three terms per year. School enrollment is verified via school records, while attendance is monitored using biometric fingerprint readers at the start and end of each school day.

The four components of the education program CCT are as follows:

1) Household Cash Transfer (HCT): The designated household head receives two cash transfers per term, deposited into a bank account. In Kibera, the total amount transferred per term (over two payments) is 2,250 KES. In Wajir, a total amount of 3,000 KES is transferred per term. These amounts were chosen to reflect $10 \%$ of the average household expenditures over a four-month period. For the first term of each new school year, the transfer is conditional only on enrollment. For all other terms, the first of the two transfers per term is conditional on attaining at least $80 \%$ attendance during the first month; whereas the second transfer per term, which is made after the third month, is conditional on $80 \%$ attendance during the second and third months.

\footnotetext{
d In mid-2015, the official exchange rate was $98.5 \mathrm{KES}$ to $1 \$$ US.
} 
2) School Fees: School fees are paid directly to the school at the start of each term. A maximum of $1,200 \mathrm{KES}$ per term is paid for primary school and 6,000 KES per term for secondary school in Kibera. In Wajir, up to $700 \mathrm{KES}$ and 5,000 KES are provided for primary and secondary school enrollment, respectively. The maximum school fee amounts were determined based on the average fee amounts parents reported paying out of pocket during the needs assessment completed in each project site. Similar to the HCT, school fee payments are conditioned only on enrollment for the first term covered by the intervention and the first term of the new school year. Payment of the second and third term school fees are conditioned on $80 \%$ attendance during the whole of the prior term.

3) Monetary School Incentive: Once each term, schools receive an additional $500 \mathrm{KES}$ per girl enrolled in the education program-received at the same time as the school fees.

4) Schooling Kits: At the beginning of each term, girls enrolled in the education intervention receive a schooling kit with the following items: four packs of sanitary pads; two pairs of underwear; a small container of petroleum jelly; a bar of soap; and an exercise book and pen. Eligibility for receiving the schooling kit follows the same conditionality as outlined above for the school fees.

All transfers are recorded in an administrative database.

\section{Health}

This intervention focused on providing health education following the Population Council's Safe Spaces model in which girls meet in the same small groups once weekly under the guidance of an adult female mentor from the community. ${ }^{7}$ The AGI-K Safe Spaces groups are segmented by age at enrollment (11-12 versus 13-15 years) in Kibera and by age at enrollment and/or schooling status in Wajir (11-12 versus 13-14 years; in school versus out of school). The health education curriculum was developed from those used in similar interventions but was modified by the research team and implementing partners for each age group and project site to ensure that the teachings were culturally appropriate and acceptable for their respective communities. It includes education on a variety of health topics, including hygiene, nutrition, HIV/AIDS, sexual and reproductive health, communication and negotiation skills, gender norms, sexual and gender-based violence, and early marriage.

The groups meet at locations within the community that are deemed appropriate and safe for young girls, including community halls, schools, churches, and mosques. The girls' attendance at the weekly meetings is monitored and recorded by the mentors in the administrative database. Additionally, mentors attempt to contact girls who are absent from the meetings, including making home visits to girls who are repeatedly absent.

\section{Wealth Creation}

The wealth creation intervention provides financial and savings education and is also delivered using the Safe Spaces model as described above. The curriculum is designed to help girls in developing basic moneymanagement skills so that they can begin to build economic assets. This component also includes the opportunity for girls to begin putting into practice the lessons they have learned in budgeting, saving, and differentiating between wants and needs. The girls in Kibera were assisted in opening an SMATA Youth Account with the Kenya Post Office Savings Bank (Postbank) upon completion of the first unit of the financial education sessions. These accounts are managed by the girls, although to open the account and make withdrawals they are required to assign an adult as a co-signatory. The account has a minimum operating balance of $200 \mathrm{KES}$, which was provided by the program. The girls are also provided with an additional $300 \mathrm{KES}$ to deposit into their accounts, for a total of 500 KES. In Wajir, girls received a home bank (piggy bank) with 300 KES already deposited. Girls in both sites will be provided with an additional 300 KES to be deposited at the start of the second year of the intervention. These transactions are recorded in the administrative database.

\section{INTERVENTION IMPLEMENTATION STATUS}

Table 1 provides a status summary for all intervention components across both Kibera and Wajir prior to initiating qualitative data collection. For the violence prevention component, all CC groups (seven in total) were active in Kibera at the time of data collection. In Wajir, although 79 groups had been formed, they were in the early stages of the dialogue process by the time data collection started due to delays in program implementation. Of those eligible for the education component, 90\% of girls in Kibera and 83\% in Wajir were participating as of the end of April and had received their schooling kits for Term 3 of 2015 and Terms 1 and 2 of 2016. HCT and school fees had also been remitted. In addition, both sites had several active Safe Spaces groups being led by a number of trained mentors. In Kibera, girls had opened savings accounts, while in Wajir, home banks had been distributed to girls in groups that had completed the first five financial education sessions. 
Table 1. Intervention Implementation Summary Status Report as of April 2016

\begin{tabular}{|l|l|l|}
\hline \multirow{2}{*}{ Intervention Component } & \multicolumn{2}{|c|}{ Study Site } \\
\cline { 2 - 4 } & Kibera & Wajir \\
\hline \hline Violence Prevention & $\begin{array}{l}7 \text { active Community Conversation } \\
\text { groups led by 14 facilitators }\end{array}$ & $\begin{array}{l}77 \text { out of } 120 \text { facilitators trained } \\
79 \text { Community Conversation } \\
\text { groups formed, but groups were in } \\
\text { the early stages of the dialogue } \\
\text { process as of May 2016 due to } \\
\text { delays in program implementation }\end{array}$ \\
\hline Education & $\begin{array}{l}1,776 \text { girls participating out of } \\
1,976 \text { eligible (90\%) } \\
\text { Household cash transfers, school } \\
\text { fees and kits distributed in Term 3 } \\
\text { of 2015 and in Terms 1 and 2 of } \\
2016\end{array}$ & $\begin{array}{l}\text { 2,292 girls participating out of } \\
\text { fees and kits distributed in Term 3 } \\
\text { of 2015 and in Terms } 1 \text { and 2 of } \\
2016\end{array}$ \\
\hline Health & $\begin{array}{l}40 \text { active Safe Spaces groups led } \\
\text { by } 51 \text { trained mentors }\end{array}$ & $\begin{array}{l}73 \text { active Safe Spaces groups led } \\
\text { by 41 trained mentors }\end{array}$ \\
\hline
\end{tabular}




\section{Qualitative Study Methodology}

\section{STUDY POPULATION}

The qualitative study population included girls who participated in the Baseline Survey, as well as Community Conversations (CC) committee members (violence prevention-only arm) and key community stakeholders, including local government officials, religious leaders, school heads and teachers, Safe Spaces mentors, CC facilitators, and parents of beneficiary girls. A combination of in-depth interviews (IDIs) and focus group discussions (FGDs) were completed in both project sites, with a total of 79 respondents from Kibera and 70 from Wajir (see Table 2).

TABLE 2. Number of In-Depth Interviews (IDIs) and Focus Group Discussions (FGDs) Conducted by Site and Respondent Type

\begin{tabular}{|l|c|c|c|c|c|}
\hline \multirow{2}{*}{ Respondent Type } & \multicolumn{2}{|c|}{ IDIs } & \multicolumn{2}{c|}{ FGDs (\# of respondents) } & Total \\
\cline { 2 - 6 } & Kibera & Wajir & Kibera & Wajir & Respondents \\
\hline Adolescent & 24 & 32 & - & - & 56 \\
\hline Parent & 6 & 6 & - & - & 12 \\
\hline Safe Spaces Mentors & - & - & $2(17)$ & $2(18)$ & 35 \\
\hline CC Facilitators & - & - & $1(7)$ & - & 7 \\
\hline $\begin{array}{l}\text { School } \\
\text { Heads/Teachers }\end{array}$ & - & 3 & $2(19)$ & - & 22 \\
\hline Gatekeepers & 6 & 11 & - & - & 17 \\
\hline Total Respondents & 36 & 52 & $5(43)$ & $2(18)$ & 149 \\
\hline
\end{tabular}

Respondents were purposively sampled based on key characteristics. When possible, adolescents were sampled by study arm, schooling status, and participation in program activities (e.g., regularly attending Safe Spaces vs. not regularly attending, receiving vs. not receiving the household cash transfer). In Kibera, girls randomized to receive the wealth creation intervention were also sampled by savings account status (i.e., those who had opened an account vs. those who had not). In Wajir, because of the cluster randomization approach used, one village was randomly selected per study arm so that the four villages chosen (Adan Awale, Dasheq, Kursin, and Meri) represented differing districts and program participation rates. Adult respondents were sampled by gender, when applicable, and other characteristics including: public vs. private school and small vs. larger schools (for school heads and teachers), and level of capacity and performance (for mentors).

\section{DATA COLLECTION PROCEDURES}

Interviewers and moderators were trained over the course of five days by study investigators before conducting the IDIs and FGDs. Each site had four interviewers-three female and one male. The training covered topics such as research ethics, qualitative research and facilitation techniques, interviewer conduct, and transcription. The training sessions also included mock interviews and a day of pilot-testing in each site whereby the interviewers were overseen by project staff members and study investigators, and thereafter given feedback. After the pilot testing, the interview guides were reviewed and revised prior to the initiation of data collection.

Following the identification of participants, the trained interviewers obtained informed consent and conducted the IDIs and FGDs in the household or other public spaces that still allowed for adequate visual and auditory privacy, such as community halls, churches, and schools. For interviews with adolescent girls, informed consent was obtained from their parents/guardians and from assent obtained from the girls. All interviews with adolescent girls were conducted by a female interviewer. In Kibera, interviews were conducted one-on-one. While it was the intention for interviews to be conducted one-on-one in Wajir, because of social and cultural norms in the region, it was difficult for girls to feel comfortable and open up to the interviewer when alone. As a result, interviews in Wajir were conducted with two to three adolescent girls to ensure they were comfortable in the interview setting. Prior to 
initiating group discussions, adolescent and adult respondents were reminded of the importance of ensuring confidentiality. All IDIs and FGDs in Kibera and Wajir were completed by late May, 2016.

\section{RESEARCH INSTRUMENTS}

Interviewers and focus group moderators followed semi-structured interview guides that provided main questions and additional probes to elicit in-depth responses. The guides were developed collaboratively by the Population Council and APHRC, and included questions and possible probes on the following topics, where applicable to the respondent type and/or study-arm assignment: general feedback on the AGI-K project as a whole; interaction with staff from Plan International or Save the Children; experience with the education support program, conditional transfers, and biometrics; experience with the Safe Spaces meetings and health and wealth creation education curriculum; and experience with CC meetings and interactions with facilitators or other committee members. Additional topics were also discussed during IDIs and FGDs for exploratory purposes, and included questions on attitudes and perceptions on school switching, gender norms, self-efficacy, and community violence. The guides were translated to Swahili (for Kibera) and Somali (for Wajir), pilot-tested, and revised based on interviewer feedback prior to the initiation of data collection.

A brief Sociodemographic Form was completed for each IDI and FGD respondent at the time of the interview or discussion. The form captured information on the study site, study arm, village of residence, respondent age, highest level of education, religion, occupation, marital status, and living arrangement (adolescents only).

\section{QUALITATIVE ANALYSIS}

All interviews and focus groups were tape-recorded with participant permission and transcribed verbatim. All tape recordings were first transcribed in the language of the interview, a mix of English and Swahili in Nairobi and Somali in Wajir, and subsequently translated into English. Following translation, all transcripts were validated and reviewed for quality assurance by a second transcriber prior to being coded. No personal identifying information, other than the assigned participant identification numbers, were included in the transcriptions.

Following transcription, all IDI and FGD transcripts were coded for emerging themes by a qualitative data analyst and a trained research assistant using ATLAS.ti software. The analysis involved first developing a coding dictionary based loosely on the structure of the interview guides. This coding dictionary was developed by the analyst trained in identifying key concepts/codes that are useful for summarizing the results and subsequently reviewed by project research staff. The coding dictionary was then input into ATLAS.ti and relevant "codes" were attached to the corresponding concepts mentioned within each transcript.

To begin, a few transcripts were double-coded to ensure understanding in the interpretation of codes and their proper usage. Following this process, nine in-depth interview transcripts (approximately $12 \%$ of the total number of transcripts) were selected to run tests of inter-coder reliability (ICR) using Coding Analysis Toolkit (CAT), a free online service by the Qualitative Data Analysis Program (QDAP). In using CATs comparison tools, double-coded transcripts were loaded as datasets into the program so that ICR kappa coefficients could be obtained for 14 randomly chosen, pre-selected codes, as well as for all of the codes together. A kappa score of 0.61 or greater was considered acceptable and indicated good inter-coder reliability. Whenever a kappa score of less than 0.61 was obtained, the coders completed a side-by-side comparison and reconciliation occurred prior to completing any additional transcripts. Furthermore, the primary analyst reviewed a random assortment of interview transcripts completed by the second analyst. All focus group transcripts were coded by both analysts together. After all transcript and focus groups transcripts had been coded, output for all relevant codes were generated and used for analysis and the write-up of the report. Word-for-word quotations are presented to illustrate the key issues and themes that emerged.

\section{ETHICAL CONSIDERATIONS}

The study protocol was approved by the Population Council Institutional Review Board and the AMREF Ethical and Scientific Review Committee. In addition, the protocol was reviewed by the Kenyan National Commission for Science, Technology and Innovation to obtain research permits for study investigators. 


\section{Qualitative Study Results}

\section{DEMOGRAPHIC CHARACTERISTICS OF RESPONDENTS}

The demographic characteristics of adolescent and adult respondents from Kibera and Wajir are presented below. The tables highlight some of the similarities and differences between respondents from the two study sites.

\section{Background Characteristics of Adolescent Respondents}

Table 3 presents the distribution of adolescent respondents' demographic characteristics by study site. The mean age in years of respondents in Kibera and Wajir were similar at 13.42 (1.02) and 12.94 (1.11), respectively. Results show that all study arms were well represented across both study sites. In Wajir, school attendance rates and grade attainment levels were lower than in Kibera. Whereas all girls in Kibera were currently enrolled in school, $12 \%$ of respondents in Wajir reported that they were not currently enrolled in school at the time of the interview. The majority of respondents in Kibera were Christians-with $67 \%$ Protestant and $12 \%$ Catholic. All of the girls in Wajir reported being Muslim. In addition, all of the girls across both study sites reported to have never been married and the majority lived with both parents (58\% in Kibera; $56 \%$ in Wajir).

TABLE 3. Demographic Characteristics of Adolescent Respondents by Study Site ${ }^{1}$

\begin{tabular}{|c|c|c|}
\hline \multirow[b]{2}{*}{ Characteristic } & \multicolumn{2}{|c|}{ Study Site } \\
\hline & $\begin{array}{l}\text { Kibera } \\
(\mathrm{N}=24)\end{array}$ & $\begin{array}{c}\text { Wajir } \\
(\mathrm{N}=32)\end{array}$ \\
\hline \multicolumn{3}{|l|}{ Age (years) } \\
\hline Mean (standard deviation) & $13.42(1.02)$ & $12.94(1.11)$ \\
\hline Range & $12-15$ & $11-16$ \\
\hline \multicolumn{3}{|l|}{ Study Arm, n (\%) } \\
\hline V-only & $6(25 \%)$ & $8(25 \%)$ \\
\hline VE & $6(25 \%)$ & $8(25 \%)$ \\
\hline VEH & $5(21 \%)$ & $8(25 \%)$ \\
\hline VEHW & 7 (29\%) & $8(25 \%)$ \\
\hline \multicolumn{3}{|l|}{ Schooling Status, n (\%) } \\
\hline Currently Enrolled in School & $24(100 \%)$ & $28(88 \%)$ \\
\hline Not in School & $0(\%)$ & $4(12 \%)$ \\
\hline \multicolumn{3}{|l|}{ Highest Level of Education Completed, n (\%) } \\
\hline No Schooling/No Grade Completed & $0(0 \%)$ & $4(12 \%)$ \\
\hline Class 1-4 & $2(8 \%)$ & $12(38 \%)$ \\
\hline Class $5-8$ & $22(92 \%)$ & $16(50 \%)$ \\
\hline \multicolumn{3}{|l|}{ Religion, n (\%) } \\
\hline Muslim & $5(21 \%)$ & $32(100 \%)$ \\
\hline Catholic & $3(12 \%)$ & $0(0 \%)$ \\
\hline Protestant & $16(67 \%)$ & $0(0 \%)$ \\
\hline \multicolumn{3}{|l|}{ Living Arrangement, n (\%) } \\
\hline Both Parents & $14(58 \%)$ & $18(56 \%)$ \\
\hline
\end{tabular}




\begin{tabular}{|c|c|c|}
\hline \multirow{2}{*}{ Characteristic } & \multicolumn{2}{|c|}{ Study Site } \\
\cline { 2 - 3 } & $\begin{array}{c}\text { Kibera } \\
(\mathrm{N}=24)\end{array}$ & $\begin{array}{c}\text { Wajir } \\
(\mathrm{N}=32)\end{array}$ \\
\hline \hline Mother only & $8(33 \%)$ & $5(16 \%)$ \\
Father only & $1(4 \%)$ & $1(3 \%)$ \\
Other relatives & $1(4 \%)$ & $8(25 \%)$ \\
\hline Marital Status, n (\%) & & $32(100 \%)$ \\
Never Married & $24(100 \%)$ & \\
\hline Occupation, $\mathrm{n}$ (\%) & & $28(88 \%)$ \\
Student & $24(100 \%)$ & $4(12 \%)$ \\
None ${ }^{2}$ & $0(0 \%)$ & \\
\hline
\end{tabular}

1 Percentages may not sum to $100 \%$ due to rounding.

2In Wajir, the four respondents who did not list an occupation were those who had never attended school.

\section{Background Characteristics of Adult Respondents}

Table 4 presents the distribution of adult respondents' demographic characteristics by study site. Adult respondents included parents of beneficiary girls, Safe Spaces mentors, community gatekeepers, and school heads or teachers. In Kibera, CC facilitators were also included. The mean (SD) age in years of respondents in Kibera and Wajir were similar at 34.07 (11.34) and 33.21 (12.42), respectively. Similar to the demographic characteristics of adolescent respondents, school attendance rates and grade attainment levels were lower in Wajir than in Kibera. In Wajir, 34\% of respondents reported that they had no formal schooling, whereas in Kibera, only one adult (2\%) reported that they had no formal schooling. The majority of respondents in Kibera were Christians, with $60 \%$ being Protestants and $25 \%$ being Catholic. Nearly all of the adult respondents in Wajir reported being Muslims. The majority of respondents in both study sites reported that they were married $(62 \%$ in Kibera; 63\% in Wajir). In addition, the respondents represented a range of occupations, including Safe Spaces mentors, teachers, religious leaders (e.g., sheikh or imam), government officials (e.g., village chief), businessmen or women, causal laborers in Kibera, and pastoralists in Wajir.

TABLE 4. Demographic Characteristics of Adult Respondents by Study Site ${ }^{1}$

\begin{tabular}{|c|c|c|}
\hline \multirow[b]{2}{*}{ Characteristic } & \multicolumn{2}{|c|}{ Study Site } \\
\hline & $\begin{array}{l}\text { Kibera } \\
(\mathrm{N}=55)\end{array}$ & $\begin{array}{c}\text { Wajir } \\
(\mathrm{N}=38)\end{array}$ \\
\hline \multicolumn{3}{|l|}{ Age (years) } \\
\hline Mean (SD) & $34.07(11.34)$ & $33.21(12.42)$ \\
\hline Range & $20-70$ & $18-71$ \\
\hline \multicolumn{3}{|l|}{ Respondent Type, n (\%) } \\
\hline Parent & $6(11 \%)$ & $6(16 \%)$ \\
\hline Safe Spaces Mentor & $17(31 \%)$ & $18(47 \%)$ \\
\hline CC Facilitator & $7(13 \%)$ & $0(0 \%)$ \\
\hline School Head/Teacher & 19 (35\%) & $3(8 \%)$ \\
\hline Gatekeeper & $6(11 \%)$ & $11(29 \%)$ \\
\hline \multicolumn{3}{|l|}{ Highest Level of Education Completed, n (\%) } \\
\hline No Schooling/No Grade Completed & $1(2 \%)$ & $13(34 \%)$ \\
\hline Class 1-7 & $2(4 \%)$ & $1(3 \%)$ \\
\hline
\end{tabular}




\begin{tabular}{|c|c|c|}
\hline \multirow[b]{2}{*}{ Characteristic } & \multicolumn{2}{|c|}{ Study Site } \\
\hline & $\begin{array}{l}\text { Kibera } \\
(\mathrm{N}=55)\end{array}$ & $\begin{array}{l}\text { Wajir } \\
(\mathrm{N}=38)\end{array}$ \\
\hline Primary School & $5(9 \%)$ & $1(3 \%)$ \\
\hline Secondary School & $12(22 \%)$ & $13(34 \%)$ \\
\hline College/University & $15(27 \%)$ & $6(16 \%)$ \\
\hline Diploma (Certificate) & $20(36 \%)$ & $4(11 \%)$ \\
\hline \multicolumn{3}{|l|}{ Religion, n (\%) } \\
\hline Muslim & $8(15 \%)$ & 37 (97\%) \\
\hline Catholic & $14(25 \%)$ & $0(0 \%)$ \\
\hline Protestant & $33(60 \%)$ & $1(3 \%)$ \\
\hline \multicolumn{3}{|l|}{ Marital Status, n (\%) } \\
\hline Never Married & 17 (31\%) & $14(37 \%)$ \\
\hline Married & $34(62 \%)$ & $24(63 \%)$ \\
\hline Widowed/Divorced & $4(8 \%)$ & $0(0 \%)$ \\
\hline \multicolumn{3}{|l|}{ Occupation, $\mathrm{n}(\%)^{2,3}$} \\
\hline Safe Spaces Mentor/CC Facilitator & $15(28 \%)$ & $18(47 \%)$ \\
\hline School Teacher & $18(33 \%)$ & $3(8 \%)$ \\
\hline Religious Leader & $1(2 \%)$ & $6(16 \%)$ \\
\hline Government Official & $3(6 \%)$ & $4(11 \%)$ \\
\hline Businessman/woman & $2(4 \%)$ & $2(5 \%)$ \\
\hline Casual Laborer & $5(9 \%)$ & $0(0 \%)$ \\
\hline Housewife/Pastoralist & $0(0 \%)$ & $5(13 \%)$ \\
\hline Therapist/Social Worker/Volunteer & $6(12 \%)$ & $0(0 \%)$ \\
\hline Other 4,5 & $5(9 \%)$ & $3(8 \%)$ \\
\hline
\end{tabular}

1 Percentages may not sum to $100 \%$ due to rounding.

${ }^{2}$ Responses are not mutually exclusive.

3Missing: $n=2$ in Kibera.

4Other occupations reported in Kibera included: NGO field coordinator $(n=1)$; community social mobilizer $(n=1)$; housekeeper $(n=1)$; Jua kali (informal small business owner) $(n=1)$; artist $(n=1)$.

5Other occupations reported in Wajir included: community gatekeeper $(n=1)$; parent $(n=1)$; and shopkeeper $(n=1)$

\section{EDUCATION SUPPORT PROGRAM}

\section{Summary of Key Education Support Findings}

Most program beneficiaries from both study sites reported satisfaction with the education intervention, which included the household cash transfer (HCT), having school fees paid, and receiving the schooling kit, Benefits described included decreased financial burden, improvements in school attendance and enrollment, and increased self-esteem and confidence among enrolled adolescent girls. However, despite repeated community sensitization efforts in both study locations, study findings also highlighted remaining misconceptions and concerns about the education support program. For example, in both Kibera and Wajir, many beneficiaries were unaware that the program only pays a fraction of the girls' total school fees and that parents may still be responsible for additional payments. 


\section{Household Cash Transfer and School Fees}

Adolescent, parent, and school head and teacher respondents in both Kibera and Wajir consistently reported satisfaction with the school fees and HCT programs. Specifically, many respondents noted a decreased financial burden, resulting in having more money available for other items or household goods. For example, one parent from Kibera described using the money received to buy food and invest in her small business.

It has helped me for sure because even when that money comes we also buy food for the children because it doesn't get all spent up, yes, I have to remain with 300 or $400 \mathrm{KES}$, then I take even if it's 200, you know I have a small business, I invest in business too... I operate a kiosk, these small things and I even roast maize sometimes in the evening.

Kibera parent respondent, female, age 30, VEHW

In addition, several respondents credited the school fees payments with improving school attendance and enrollment, increasing understanding of the importance of education, and improving self-esteem and confidence. A few adolescents in Kibera said that they are no longer being chased away from school as a result of an inability to pay school fees. Adolescents and parents in Wajir noted that girls who had dropped out or who had never been taken to school have now been enrolled.

What I like is that it helps us girls to have self-esteem. It also pays our fees and helps our parents if they don't have money. Sometimes let us say that you have been sent away from school and your parents don't have money so you see AGI-K will pay fee for you so that you won't be sent away from school again. Kibera adolescent respondent, age 14, VEHW

Before this group, only boys used to go to school but now since our fees are paid by Save the Children, many girls got the opportunity to go to school and learn.

Wajir adolescent respondent, age 13, VEHW

School heads and teachers also recognized an increase in attendance and enrollment in school among adolescent girls in their respective communities and an overall improvement in student self-esteem, confidence, and classroom performance since the initiation of the program.

For most of them you would say there is a very direct impact in their behavior. Self-confidence, selfesteem... And even in terms of discipline you would say because I think at the back of their mind, I always imagine that either it's at the back of their minds that they stand to lose the benefits that they have if they misbehave or the mentorship is working.

Kibera school teacher respondent, female, age 26

For fees the girls do not miss lessons in search for money, they do not delay from school in search for money, they are very comfortable and they are not sent home in search of any levies unlike other children who are sent home at the end of every month... It has helped in enrolling some girls who were not in school initially.

Wajir head teacher respondent, male, age 45

Well, what I like about the program is that it is something motivating to the girls. Mostly when the girls feel like that they have been sponsored. They know that somebody appreciates their education and most of them are putting in more effort in their education and they are always in school and we have seen great improvement in their performance. 
A parent in Kibera even added that her daughter no longer had to transfer schools or repeat classes as a result of the paid school fees received from the AGI-K education support program. Moreover, several parents and teachers in Wajir reported that the program has motivated them to take their daughters to school, explaining that poverty within the community previously contributed to an inability for families to take their children to school.

What I see going on so well is, it is helping me a lot by paying school fees for my daughter because it is something that really used to annoy me in my heart because I had very low income because my child was being sent home because of lack of school fees, [name] repeated a class because of lack of school fees and she could even transfer schools that is why she is where she is today, right now she could have been in form one.

Kibera parent respondent, female, age 36, VEHW

Due to the support they receive from this program the number of girls who are joining secondary schools has increased because they motivated now and they are willing to study hard, complete their primary education and join high school...School dropout was common and it has greatly reduced.

Wajir parent respondent, male, aged 42, VE

It has reduced the burden from the parents because here the parents are poor; they have no economic activities to support their children so it has lessened the burden for the parents...So this has made easier for the girls to be in school because they are not a burden to their parents anymore.

Wajir deputy head teacher respondent, male, age 41

Despite providing general positive feedback regarding the household cash transfer, several adolescents and parents from both Kibera and Wajir experienced operational difficulties, reporting that the household cash transfer was paid late or was never received, that an account had not been opened, or described difficulties keeping their accounts active or accessing the money from their bank.

My parent doesn't get the money...They don't have an account.

Wajir adolescent respondent, age 14, VEHW

I also don't know because they had told me to take... my equity bank card, so I went and made a photocopy and took it to them so now I don't know how it went and I did not receive any money while others have received, so I don't even know what is going on.

Kibera parent respondent, female, age 36, VEHW

One parent in Wajir specifically noted the dissatisfaction and inconvenience related to withdrawing the household cash transfer because of the costs they would accrue travelling to the nearest bank. In response to some of these issues, two parents in Wajir suggested increasing the amount of the household cash transfer, while another Wajir parent requested that those who experience account problems be assisted, as it is not fair that some receive the cash transfer while others do not.

[Name of staff] told us that we have 1,500 KES in our account in Wajir. Though, if I may ask you: can one travel from here all the way to Wajir just to collect 1,500 KES? I hear there are some parents who have collected their money from Wajir... you see the fare from here to Wajir is $500 \mathrm{KES}$ and coming back is another $500 \mathrm{KES}$ a total of 1,000 KES, and what I am collecting from Wajir is 1,500 KES, It is not realistic.

Wajir parent respondent, female, age 39, VEHW 
In Wajir, one parent's concern alluded to possible misconceptions about the AGI-K program at the community level. As illustrated in her statement below, she has yet to withdraw or use the money received from the household cash transfer because she had heard that the money was being given in exchange for girls

The biggest fear I have is that I heard our girls will be made Christians and taken to another country. Personally I haven't used the money I received from this program ... because I was told that this money is given in an exchange for our daughters and that's why I kept the money so that in future when they come and claim our daughter we will give them their money.

Wajir parent respondent, female, age 36, VEHW

School heads and teachers in Wajir were also aware of issues experienced by parents in receiving the household cash transfer. One school head said that when parents do not receive their cash transfer, it creates mistrust between the school and the parent, and suggested that parents be paid on time and manually, rather than being paid through an account. Another head teacher in Wajir noted the difficulty parents have with their accounts, and thus should be given additional assistance from program staff in going to the bank and opening their accounts.

Sometimes the parents don't receive the money and because they are illiterate they think that the head teacher has their money and it brings big mistrust between the school head teacher and the community. It is good that they normally dwell on an account, but I feel sometime they can just give out the money manually, by taking their thumb prints so as to clear that mistrust.

Wajir school head teacher respondent, male, age 29

What they are saying is that they never got anything up to now because some of their bank accounts have problems. All the same some are benefiting while others have not gotten anything... Find out what the problem is and find amicable solutions... Follow up this parent please. If you can find the specific bank that they can open an account with, it will be well for them because traveling in the name of going and opening an account sometimes is tedious.

Wajir head teacher respondent, male, age 45

Additionally, a few adolescents and parents in Kibera reported experiencing delays in the payment of school fees or said that school fees had never been paid at all, forcing the parent to have to pay the full amount owed to the school for fees.

When it comes to tuition money that is where the problem is because you will find the teacher telling you that tomorrow you should come with money or you will be beaten and sent away. What if the parent doesn't have money at the moment and AGI-K has not sent any money? So what I would suggest is that they send that money earlier.

Kibera adolescent respondent, age 12, VEH

A few school heads and teachers in Kibera also described the late payment of fees, while others described a misconception among parents that the program covers the full amount of school fees owed, creating problems for the school in collecting the remaining balance from parents. As a result, some school heads and teachers requested that school fees be paid on time, to increase the amount of school fees paid, and for mentors to meet with parents again to clear up confusion around what support is provided by the program.

Exactly, and the other bit of it is failure of parents to really understand what is going on. It is only 1,200 KES that is sent to the school for a whole term. The parents expect this to cover for everything. The whole year. 
For example they are supposed to pay around 2,000 KES for the standard seven and eight and the mentor or Plan gives 1,200 KES, the rest of the money they expect now the school to do what? To pay in. I think it has been a problem and a number of times we have complained and I think it would be right [for] the mentors to meet the parents so again we can be able to tackle this issue once and for all.

Kibera school head respondent, male, age 30

When school heads and teachers were asked about whether or not parents are notified when the fees had been paid to the school, the responses were mixed. In Kibera, some said that parents were in fact notified and told the amount of the balance that remained, while one school head explained that it was the mentor who normally informed parents, as they have more direct communication with Plan staff. This school head also added that sometimes the parents know when the money has been remitted to the account before the school is notified. The other school heads and teachers in Kibera said that they did not communicate with parents regarding fee payment and assumed that parents knew when the fees were being paid and that they were responsible with paying the balance.

Respondent 1: Actually we don't inform the parent, but what we normally do, we normally assume that the parent is aware of the balance that he/she has to pay. So once this amount is deposited in the account, as long as he/she clears the balance, we don't see the need of informing him/her because, the term will end minus the kid being sent home so he/she will know that everything is okay. [male, age 27]

Respondent 2: In our school once we identify that the money has been deposited in the school account, we always inform the parents to come and get the receipt. [female, age 28]

Kibera school teachers group discussion

We are always informed by mentors because they have direct communication from Plan. And as we are informed, in their sittings, the mentors usually have sessions with parents and children. Sometimes as a teacher, you don't even know that the money has been remitted, but the children will come and tell you, "Teacher we were told that the money has been deposited." Yeah, and in the same way they communicate to the parents. Sometimes the parents are aware even before you are aware that the money is in the account.

Kibera school head respondent, male, age 35

In Wajir, one school head and one head teacher said parents are informed; however, one of these teachers said that the parents are informed via their children. This teacher went on to explain that the child is informed at the month's end and is entrusted with relaying that information to the parent. The other head teacher interviewed in Wajir was not sure if or how parents were informed about school fee payments.

They are informed through the girls. For example, during the end of the month when the other children are bringing their school levies, we inform the girls that the levies for this month have been catered for by AGI-K program, so inform your parents you're not paying this and this.

Wajir head teacher respondent, male, age 45

Another difficulty encountered involved girls randomized to the violence prevention only (V-only) intervention arm recognizing that they were not receiving the same benefits as other girls in the program. One adolescent in Kibera and four adolescents in Wajir requested that they should receive the same benefits as other girls, such as school fees support and school kits. 
If you start helping them, I would also like you to help me with my school fees and buy me books and sanitary pads... My mom and dad have a problem with paying my fees. I was even at home last week because of school fees. They were able to pay for me 2,000 KES, but it is supposed to 13,000 KES but they were able to pay only 2,000 KES so I would just urge them to help me pay my school fees.

Kibera adolescent respondent, age 15, V-only

Respondent 1: We should be given what other girls are getting... School fees and the items they buy girls when they are going back to school. [age 12]

Respondent 2: We should be given school fees just like the other girls. [age 13]

Wajir adolescent respondents, V-only

School heads and teachers also discussed that the program was creating a disparity between the girls chosen into the program and those who are not. One school head in Kibera noted the elevated self-esteem of those in the program, while girls not in the program felt left out. Another head teacher in Wajir suggested enrolling all girls within the school into the program because parents and school girls wonder why some have been chosen while others have not. There also exists a potential for information-sharing in schools between girls in the program and those who are not. For example, some of the teachers in Kibera discussed girls in the program sharing what they had learned in Safe Spaces on sexual and reproductive health topics with the other girls in school who were not enrolled in the program.

Someone talked of the girls being more courageous to talk to you. There is that aspect of elevated selfesteem. But you know, as the self-esteem is elevated, there is also the other aspect of the girls feeling special. They imagine it's just us, you know. And in my school, this is the case. Every now and then the other girls are very curious, they really want to ... you know you look at their faces and you know these people really feel left out. So these other girls who were chosen, I think they also feel like they are quite above the rest and so there is that pride and you know, that comes with the self-esteem.

Kibera school head respondent, male, age 35

I could have suggested that we empower parents more and let's try to engage, capture, and enroll all girls outside school... parents may also require to adjust the incentive given or the number of children captured in the locality... In other words, the number of children currently served is more minimal compared to the parents ... because there are 150 girls almost 60 are captured. If the program is capturing all girls in school, some girls are wondering why a girl is captured in the school and another girl of the same class is not captured... So parents see that as a big disparity. If it is capturing girls in school, then all should be captured.

Wajir head teacher respondent, male, age 45

Yes, they are different in terms of reproductive health. I think they have been helping the teacher nowadays ... I think the education they are given then pass it on to the other girls. So the teacher does not have to deal with those problems deeply like the other times... You see we have like clubs, so whenever we have now we have those clubs; before we have the teacher who is supposed to take them through it. The girls have already organized them, they have already started talking to the other girls. So when the teacher comes, he just continues from where they have left. So they are a bit higher.

Kibera school teacher respondent, male, age 34 


\section{Schooling Kit}

Adolescents and parents in both Kibera and Wajir most commonly reported satisfaction with the sanitary pads provided in the schooling kits. Many parents from both project sites described a decreased burden on them to provide sanitary pads for their daughters, while some parents in Wajir added that girls no longer have to miss school during menstruation since they have now been provided pads and have learned how to use them.

She got pads, two pants, and books and a pen and a pencil...all those things help her. I never had the money to buy her all that; she used pieces [of] cloths and right now she even knows how to use pads and now she tells me that she doesn't have any problem with that.

Kibera parent respondent, female, age 36, VEHW

This program helped my daughter with a kit containing always (sanitary towels), which is of essential use to her. Before the inception of this program, she used to stay at home whenever she is on her monthly periods, but now she can go to school comfortably... This motivates them to be in school all the time and the fear of being embarrassed in case the desks/chairs are soiled is gone.

Wajir parent respondent, female, age 38, VE

I like the pads because it really helps me, you know that every month I experience my menses, and also the petroleum jelly helps me because there are times that we do not have any in the house so I will use it instead. There are times that I do not have underwear and I cannot go asking my father for the money to buy underwear because I find it really hard to do. Therefore the underwear really help me.

Kibera adolescent respondent, age $13 \mathrm{VEH}$

Adolescents from both project sites discussed their general happiness in being provided with the items in the school kit since before this program there was never enough money to buy items like sanitary pads, underwear, and soap. In addition, adolescents in both Kibera and Wajir specifically mentioned being able to assist friends or family members by giving them unused items from their school kits, for example, soap, underwear, or unneeded sanitary pads for those who had not yet started menstruating. School heads and teachers from Kibera and Wajir also credited the schooling kits with easing the burden on the school in having to provide sanitary pads.

It helps us when we want to shower, we shower with it. Like there was no money in the house and my mother has a newborn baby, so when I brought in the soap it really helped my baby brother because that is what he used to shower.

Kibera adolescent respondent, age 14, VEHW

Respondent 1: The four packets each contain eight pieces and it helps me a lot... My elder sisters can use it when they are in their cycle. [age 13]

Respondent 2: I have never used it, but I give it to my elder sisters and other girls who do not have. [age 13]

Respondent 3: I have never used it myself, but I give it to the other girls who cannot afford to buy it. [age $14]$

Wajir adolescents group discussion, VEHW

Again I want to believe that in my school, the project has tried to reduce the pressure on the school regarding sanitary towels because when these girls start menstruating there is too much pressure in the reproductive health office and the girls are like, heh, teacher, it has come, what do I do, so we have emergency pads. It reaches a point when the school can no longer support the girls, but now that the program was brought, the girls in the program even assist other girls with pads. 
There were sanitary pads, exercises books, and even some pens so it has improved the performance in class because some of the girls were lacking these commodities (items) at home... They have been motivated in class and they feel somebody is recognizing them.

Wajir deputy head teacher respondent, male, age 41

Although perceptions were largely positive, several adolescents and parents in Kibera and Wajir also described their dissatisfaction with some of the items provided in the school kits, in particular the sanitary towels and the underwear. Several parents and adolescents from both project sites reported problems with the sizing of the underwear and had complaints about running out of some items, like the soap and petroleum jelly, too quickly. As one 36-year-old parent in the VE arm in Kibera noted, "These underwears that they are given, they are too small. Like the ones for [name] is not fitting her, so the one who can put it on is a small baby who is below one year." Respondents, therefore, recommended the provision of larger-sized underwear.

In addition, one 12-year-old adolescent in the VEHW arm in Wajir reported that "some [sanitary pads] are not absorbent enough," while a parent in Wajir said it was inappropriate to provide sanitary pads to girls who had not yet started menstruating.

Everything that was given to them was important except a few things like the sanitary pads because my daughter has not yet reached puberty... I don't see its importance since my daughter is a little girl.

Wajir parent respondent, female, age 39, VEHW

\section{Biometrics}

A few parents from both Kibera and Wajir provided positive feedback on the fingerprint or biometric device used for capturing school attendance, stating that the system ensures that girls are reporting to school every day. The parents in Kibera and Wajir explained it this way:

We were told that if she misses school and does not check in and check out, she will be withdrawn from the program, so it forced her to go to school so that her thumb prints can be taken.

Kibera parent respondent, female, age 36, VE

What is going well about this program is that our girls go to school every day because of the fingerprint device that captures their prints and as parents we are more concerned about our daughters' education since this program was introduced.

Wajir parent respondent, female, age 38, VE

This gadget captures the girls fingerprint in the morning, and afternoon when they are leaving school, and by doing this the teacher will know if the girl attended school or not. Due to this my daughter never misses her classes.

Wajir parent respondent, female, age 36, VEHW

Some adolescents in Kibera also said they liked the fingerprint device because it confirms that they have attended school and because they can then be confident that their school fees will be paid. One adolescent in Wajir also noted that, by using the fingerprint device to confirm school attendance, parents would receive the household cash transfer and then have money to use for purchasing other goods. 
When you arrive in the morning you just go there and place your finger and it identifies and brings up your name; then you check in. Also, in the evening before you leave you place your finger to check out and the program will help you by paying school fees if you attend school throughout. That really helps because it will identify that you come to school every day.

Kibera adolescent respondent, age 14, VEH

The money which we are given when we put our fingers on the fingerprint device helps us to sustain our need, like we buy school uniform with it.

Wajir adolescent respondent, age 12, VEHW

Most adolescents from both project sites reported frequently encountering difficulties related to the fingerprint device used to capture school attendance. In Kibera, several problems were described, including: the device not working properly or not capturing attendance; disruption of lessons when capturing attendance; and teachers not always bringing the fingerprint device or allowing girls to leave class to capture their attendance. In addition, a few adolescents in Kibera reported not being called to capture attendance consistently or said that, since program initiation, they had never used the fingerprint device to capture their school attendance. A parent in Wajir also recognized that the fingerprint device did not always capture attendance and caused some students to miss lessons.

Every time when I come early the person who is in charge of the fingerprint thing is not there. Now you have to go to class and then they come and call us in the middle of a lesson. Interrupting, yes, that is what I don't like.

Kibera adolescent respondent, age 15, VE

We used to put fingerprints long ago, nowadays we don't put ... I don't know. They used to call us, nowadays I don't see that thing. They don't call us. So I don't know where it went.

Kibera adolescent respondent, age 14, VEH

Yes, I even went to ask the teacher and he told me sometime the device cannot capture the fingerprints and since the girls are many this leads to wasting a lot of time of which they should have been in class learning... It's time-consuming and they miss class due to this.

Wajir parent respondent, female, age 38, VE

School heads and teachers in both Kibera and Wajir also expressed dissatisfaction with the fingerprint device. They commonly described the time-intensive nature of checking students in and out, the disruption caused in lessons, and device malfunctions, for example, issues in capturing fingerprints, syncing and sending data, and keeping the device charged. Most important, the head teachers were concerned that the issues they experience in using the fingerprint device would unfairly prevent girls from meeting the $80 \%$ attendance criteria, making them ineligible to receive the cash transfers. To help resolve some of the issues experienced in schools, a number of school heads and teachers in Kibera and Wajir suggested the use of a manual system or assigning the task to someone who is not a teacher so that lessons are not disrupted.

The first challenge I am facing is that sometimes those gadgets do not work and I know that they are supposed to pay the school fees, according to the $80 \%$ that the girl will have acquired in signing in and signing out. So when those gadgets do not work, then sometimes you try to seek for the assistance from the mentor that you have been given, and the action is not taken immediately. Then it tends to interfere with the whole system because there will be a problem in the payment of fees for the girl and it will affect the running of the school.

Kibera school teacher respondent, male, age 27 
For example the teacher who is in charge, in conducting the biometric has a lesson to attend and the lesson is lost because some girls are still coming for check-in. So that is also another way it has affected the school negatively... Okay, one thing I could have suggested is to change the check-in and check-out into manual register, because it is not easy for a girl to drop out of school which she has been there without incentives... So I feel they at least ease the work by accepting the school registers or they bring their own register, which the concerned teacher can mark. Because it is easier to confirm a register than to do the check-in and check-out by capturing their fingerprints.

Wajir school head teacher respondent, male, age 29

\section{School Monetary Incentive}

Most school heads and teachers provided positive feedback regarding the monetary incentive provided to schools, commonly reporting on the allotment of money for use on school development and support projects. School heads and teachers reported a variety of improvements made to schools using that money, including classroom repairs, purchasing black and whiteboards, and paying for food and exam fees. School teachers from Kibera explained the improvements that have occurred in the school in this way:

So we do receive 3,500 KES as incentives that one caters for repairs, because we have also painted the blackboard, we have repaired some of the desks and then the teacher responsible for the kit also is motivated.

Kibera school teacher respondent, male, age 34

In Wajir, two school heads reported using the monetary incentive to hire support staff or pay Parents Teachers Association (PTA) teachers and school cooks. One of the head teachers explained:

We really like it that one has assisted us on employing a PTA teacher or even paying some of the support staff in the school.

Wajir head teacher respondent, male, age 45

Some school heads and teachers in Kibera said the money was used to compensate teachers responsible for taking biometric measurements. However, some of the Kibera school heads and teachers expressed their dissatisfaction with the school monetary incentive, explaining that schools were not using the money to compensate the teachers responsible for checking students in and out using the fingerprint device. One school head recommended program staff implement a policy outlining exactly what a teacher is to be compensated for when in charge of the biometrics.

Yes but back at our place at least we have been giving out something small to the teacher who is in charge, just to do what, to make sure that he does that work, although part of his duty is to come and do what? And teach, that is what most of probably the managers, they assume now they have employed you, you are their worker and you are paid salary, so there is nothing they should do what? They should add on top of that. So again I believe it would be right if ... the people in charge... they can move around and ask, "We have these teachers who are doing this, what are you doing for them?" And again it is possible they can come up with a policy, they say for example out of the whole money give this teacher 2,000 KES.

Kibera school head respondent, male, age 30 


\section{SAFE SPACES}

\section{Summary of Key Safe Spaces Findings}

Qualitative findings highlight the perceived positive effects of the Safe Spaces meetings on the girls from both the parent and girl perspective. In Wajir, results provide early evidence for changes in attitudes toward early marriage, while in Kibera the findings indicate increased social assets, such as aspiration and self-esteem. For girls receiving the wealth creation intervention, there was a notable increase in their savings activities and financial responsibility. Adolescents from both study sites reported forming important friendships with other girls in their Safe Spaces group, thus expanding their peer networks. Mentors also discussed the perceived benefits of the program, reporting increased knowledge, self-esteem, confidence, and capacity. In both Kibera and Wajir, mentors have been able to forge important relationships with girls and parents alike, as they described their experiences with girls and parents coming to them when seeking guidance, help, and assistance.

Parents and adolescents in Kibera described a general satisfaction with the knowledge being gained from those topics covered during the sessions, particularly those revolving around menstrual hygiene and management, sexual and reproductive health, and money management. Although parents and gatekeepers in Wajir also reported satisfaction with many components of the curriculum, the research findings also highlight several misconceptions and concerns that still exist surrounding some of the topics covered within the sexual and reproductive health curriculum, such as family planning and early marriage.

\section{Safe Spaces Meetings}

\section{Knowledge Gained}

In general, adolescents and parents from both Kibera and Wajir reported satisfaction with the Safe Spaces meetings and curriculum. Many girls reported to have gained important knowledge from the meetings, for example about how to maintain hygiene and cleanliness, protect themselves from boys and against violence, eat a balanced diet, and delay sex. A parent from Kibera said they liked that their daughter learned to protect herself from abuse while walking the roads, and a couple of parents from Wajir reported satisfaction with the menstrual hygiene and management skills gained.

We learn important things that we didn't know ... like reasons to delay sex.

Kibera adolescent respondent, age 12, VEHW

When walking on the street, boys like stopping girls which is bad, and I learnt how to deal with them. Wajir adolescent respondent, age 14, VEH

Adolescents from both Kibera and Wajir reported satisfaction with the wealth creation education component of the Safe Spaces meetings, with many girls describing that they liked learning how to save money. Some of the adolescent girls in Wajir even described being able to use their savings to provide financial support to the family in buying food or buying themselves pens.

When my mum does not have anything to buy sugar with, I will give her some of the money I was saving. Wajir adolescent respondent, age 13, VEHW

Respondent 1: I have removed 20 KES to buy four colors because I didn't have a pen. [age 12]

Respondent 2: I remove 10 KES to buy [a pen]. [age 12]

Wajir adolescents group discussion, VEHW

Some of the parents from both sites also recognized an improvement in their daughters' financial literacy, explaining that they now know the importance of saving, how to save, and can demonstrate financial 
responsibility. Parents in Kibera also noted their daughters' excitement about going to the bank and learning how to open a savings account and make deposits and withdrawals.

Because the girls are learning new things. Even though, my daughter is a little girl ... she can also understand how to save and the importance of saving. For instance, she told me she was taught that if she gets 10 shillings she can buy a candy at 5 shillings and save the rest. That's quite resourceful.

Wajir parent respondent, female, age 39, VEHW

She was happy about the process of opening the account and she told me that she was so happy about the whole process of opening an account. They were also told on how to make deposits and withdrawals. All these they were taught.

Kibera parent respondent, female, age 36, VEHW

The mentors also explained how they have been able to overcome barriers that parents and teachers face in discussing sensitive topics (e.g., reproduction) because mentors can more freely talk about such things. As a result, one mentor noted that parents are very supportive of their daughters' participation in the Safe Spaces sessions:

What I like is that, you see this reproduction topic is hard and even in school you will find the teacher shying off, not all teachers open up. Then at home, if there is a girl who lives with her father, there is no way her dad will tell her about reproduction... So you see, we have come up ... we have bridged ... we have broken those boundaries and you even find that. Like I have girls who live with dad and when their parents go for CC at least they are told what girls learn. They don't want their girls to miss, because they know what the girls get there he cannot tell them. So you find that those parents are so positive and they are concerned and they cooperate. So I feel, this Safe Space has really helped a child, it has also really helped the parents.

Kibera Safe Spaces mentor respondent, age 24, VEH

Moreover, mentors mentioned that the health education curriculum has benefitted both girls and their parents. They noted that adolescent girls have learned better hygiene and now understand that menstruation is normal and not a curse for adolescent girls.

Respondent 1: Health education helps them to learn about hygiene, especially how to stay clean when they get period. [age 24]

Respondent 2: It helps them to learn that adolescence age in not something abnormal. Before, they use to get frustrated when they get their periods, but now they learnt its normal for every adolescent girl to go through this process and this has been achieved through health education. [age 30]

Respondent 3: Health education is very important because it helped the girls learn about abstinence, and how to use protection so that they will not get HIV/AIDS. [age 20]

Wajir Safe Spaces mentor respondents, VEH

\section{Changes in Behaviors and Attitudes}

Several parents from Kibera described changes in their daughter's behavior since joining the group, noting improvements in attitude, studying and reading, and financial responsibility, while in Wajir one parent reported that her daughter had increased self-esteem and confidence and was no longer shy. One of the adolescents in Kibera also described an improvement in self-esteem and confidence since participating in Safe Spaces meetings. 
Now, right now I can see changes because right now if she takes your money she will tell you that mom I have taken your money and I have done all these with it, I have even bought water. But before she never used to do that, she could find money and use it to buy biscuits and sweets and bhajia by the road, fries and eat them by the roadside, but right now she doesn't do that... Something that I am finding to be nice is that she studies a lot, and if she leaves the house she has gone to wash by the riverside. But when she is in the house she is always reading, so I see that that is something that has changed.

Kibera parent respondent, female, age 36, VEHW

My daughter used to be shy but since this group meeting started she is not shy anymore.

Wajir parent respondent, female, age 36, VEHW

They have changed me because now I have self-esteem. Like in class when we are going to represent like in social studies there are parts, so those parts are the ones the teachers give us so that we can go and present them in front of the class. So it has really helped us have self-esteem... It has helped me personally to have confidence.

Kibera adolescent respondent, age 14, VEHW

In addition, mentors from both project sites also described improvements in the girls' attitudes and behaviors, reporting elevated self-esteem and confidence, ability to share information with others, increased awareness of the importance of education, and improvements in communication skills.

I will talk about how it will impact on the girl long-term. I think it empowers them so much because they can express themselves, they can even go and teach... You can see most of the parents are illiterate ... so they can even go and teach the parents on the right ways, even the financial ways of saving money, the importance of saving that money, importance of opening an account to save the money.

Kibera Safe Spaces mentor respondent, age 33, VEHW

And then another thing, at least the girls, there are those we started with who were very low and could not open up, they were very shy. Even when you are in class mentoring them and you ask her a question, she couldn't answer, but at least now, their self-esteem has gone up. Now they can even talk and if you ask her something, she can tell you.

Kibera Safe Spaces mentor respondent, age 26, VEH

Respondent 1: The girls in my group interact for example when am teaching they discuss and participate in class, and the side of education since the program started, they actively participate in class. [age 21]

Respondent 2: In my group when I ask them about their friend[s] who are absent before they use to shy but now they tell me where their friends are and also they share ideas and problems. [age 23]

Respondent 3: Before the program they used to be shy and refuse to answer question but they really participate. Also they used to refuse to take photos during the session, but now they do agree. [age 28]

Wajir Safe Spaces mentors group discussion, VEHW

Feedback from mentors in Wajir, also described the benefits of the program in highlighting the negative consequences of early marriage practices within communities in Wajir. Mentors explained how, through the Safe Spaces teachings, adolescents in Wajir are slowly becoming empowered to speak to their parents about the negative effects of early marriage. 
Before this program, you will find a 9-year-old girl who has been booked or her hand has been asked for in marriage, but since AGI-K started every village has got a mentor which helped the girls in the program to benefit from Safe Space sessions on early marriages. They go and tell their parents that they want to continue with their education and become like their mentors.

Wajir Safe Spaces mentor respondent, age 23, VEHW

There was forced marriage, before a parent tells his/her daughter that to take blessings or curse when they want to marry off their daughter, and the girl had no choice but to accept their decision. But now since this program started, health education played a great role of educating them to stay healthy and say no to forced marriages.

Wajir Safe Spaces mentor respondent, ages 20, VEH

\section{Program Misconceptions}

Despite a general satisfaction and perceived effects on the girl child, one parent in Wajir explained a general unawareness of what is taught during the meetings and described some of the program misconceptions among community members. Some community gatekeepers in Wajir, many of whom were also parents of girls enrolled in AGI-K, also expressed concerns about the Safe Spaces curriculum and voiced fears that program and Safe Spaces meetings would lead to an erosion of morals, as well as negatively impact on certain religious and cultural practices, such as early marriage and FGM/C. One of the male gatekeepers stated that he was personally against the Safe Spaces meetings and requested that they be discontinued.

What are our girls taught in these meetings, are they taught good or bad things? I would urge you to come clear on what you are teaching our girls. If you are telling them bad things like how to date men and such, kindly refrain from that. Teach them what you would want to be taught when you were of their age. Already rumors have come up that you want to mislead our girls and sell them to men who are based in as far as America and the rest of the world. If that is what you are propagating kindly stop it.

Wajir parent respondent, female, age 39, VEHW

What is not going well is that the people in the village are all Muslims and when they see this program is targeting only girls it gives them some doubt. The other one is that FGM is a contentious issue because it's a cultural practice and it will continue. It's a must for every parent to cut their daughters whether it is a small cut or a big one, therefore prevention of FGM looks like interfering with the religion and culture of the community. You are young boys and girls who are working on a contract and you don't know beyond that, because this NGOs came from as far as UK or any other places and the people's perception is that they are spreading Christianity.

Wajir gatekeeper respondent, male, age 32, V-only

I think it will affect the girls negatively since they will not marry immediately and normally if a girl receives her menses first, second, and third time then she should get married. So as a parent you will be answerable on the Day of Judgment.

Wajir gatekeeper respondent, male, age 56, VEHW

It may lead to lack of good behavior because she is a girl... In my opinion you should do away with these meetings ... because girls will lose their good behavior. Secondly they will not attend duksi (madrasa). Sometimes they miss duksi (madrasa) so that they attend the meeting, which may lead to duksi (madrasa) drop outs. Thirdly, she will go to the meeting while her mother needs her help, that is why am saying we should do away with the meeting.

Wajir gatekeeper respondent, male, age 45, VEH 
As a way to ensure that parents are aware about what girls are learning in the Safe Spaces groups, some parents and gatekeepers in Kibera suggested that parents should be better informed about the Safe Spaces curriculum and its importance.

I don't know because my daughter did not tell me what she has been taught by her mentors and also the school teachers didn't tell us about the topics that our girls are being taught... It is important for the parents to be informed what their girls are being taught during these meetings, like this school [when] we were starting, the parents were told about the start of the school. I don't know what topics are being taught at all.

Wajir gatekeeper respondent, male, age 49, VEHW

Eeee it is good that we involve parents when they are being taken to such place so that even parents can hear what their children are being taught.

Kibera gatekeeper respondent, male, age 47

\section{Social Networks}

In general, adolescents from Kibera and Wajir reported that they formed positive relationships and friendships with other girls within their Safe Spaces group, explaining that they are able to laugh together, share what they have learned, visit each other outside of group meetings, and help each other when they are in need. Although a number of girls reported that they already knew some of the girls in their group, they described becoming even closer with these friends and being able to share with them more easily.

Some of the girls are polite and they love unity, if you have any problem they can advise you... These girls respect each other, they are humble, and they do not like quarreling... They don't like it when anyone is lonely.

Kibera adolescent respondent, age 14, VEH

There are times after we have finished the program. We start the program at 3pm and it ends at 5pm so you will find time to go out and walk with your friends. Maybe let us say one of your friends is sick you can go and pay her a visit. And you have fun along the way with your friends.

Kibera adolescent respondent, age 12, VEH

Respondent 1: I make stories with them and discuss whatever we were taught by the madam [name of mentor]. [age 14]

Respondent 2: They give me a pen when I don't have it, so through this we become friends. [age 13]

Respondent 3: We used to know each other before the group... Since the inception of the group, we become close and we can share every problem now. [age 13]

Wajir adolescents group discussion, VEHW

Respondent 1: I trust them and we share things. [age 12]

Respondent 2: I trust them very much since we discuss and share what we have. [age 14]

Respondent 3: There are those I don't trust ... because they are careless and cannot be trusted with your things. [age 13]

Wajir adolescents group discussion, VEH 
Further, most girls did not see any major differences in their relationships with the girls in the group compared to those outside of the group; however, a few girls in Wajir felt that the girls in their Safe Spaces group assisted them more than the girls not in Safe Spaces. In addition, information sharing outside the group was common amongst many of the adolescents in both Kibera and Wajir. Some even noted that by sharing some of the lessons learned in their Safe Spaces group, their friends outside of the program had shown an interest in joining.

Most of them whom I have shared with what we are taught I see they have changed... Like when it comes to choosing friends, when you advise them on that they might take you to be bad so if you tell them that and then they try to avoid, they see the difference... They have changed because you will find that when they go to different places they will find new friends who will advise them and then they will come and tell me what they had been advised by their other friends. So we tell each other good things.

Kibera adolescent respondent, age 14, VEH

Respondent 1: We meet in the school every day...we make stories and joke and I share with them what have been taught...They ask whether they can be allowed to join. [age 13]

Respondent 2: We often meet in the school and those who are not in school we meet them in the village... Yes and they ask whether they can join the group. [age 14]

Respondent 3: I meet them at school and Duksi... I discuss with them whatever we have been taught by the mentor and they say it's [a] good thing. They also ask what the procedures to be followed are so that they can be part of the group. [age 13]

Wajir adolescents group discussion, VEHW

I told them we are taught how to respect people... They said you're taught important things ... and they ask me whether they can join the group.

Wajir adolescent respondent, age 14, VEH

\section{Barriers to Attending Meetings}

All of the adolescents in Kibera reported to have missed at least two Safe Spaces meetings, while most of the girls in Wajir said they had not missed a single meeting. In Kibera, some of the reasons stated for missing a meeting included illness, traveling upcountry, working, or having to complete other jobs in the home. In Wajir, the most commonly reported reasons for missed meetings included illness and having to complete other household chores or responsibilities, for example fetching water and firewood, taking care of younger siblings, or looking after the family cattle.

No, there is this Saturday that I didn't attend... I went upcountry.

Kibera adolescent respondent, age 12, VEHW

Sometimes like when we go on Sundays, I wake up with a lot of work to do. Like when I want to wash I don't do it's early so I can even finish washing at 2:30pm, and if you go for the classes at that time you will find when the lessons are already over.

Kibera adolescent respondent, age 14, VEHW

Respondent 1: Some will not attend because they are sick. [age 13]

Respondent 2: They will be looking after the animals. [age 13]

Respondent 3: Since it's conducted on Friday evening some girls will be busy fetching water and firewood. [age 14] 
One mentor also described how gender roles can affect participation, explaining that girls are expected to take on more household responsibilities than their male counterparts.

There are some parents who still believe that these things are for the girls and these ones are for the boys. That is why you will find some during Safe Space they will say that they didn't come because the mother left her with the baby, your mother left you the baby and she knew that you are supposed to come to Safe Space. Maybe you have a brother who is free maybe at that time he has even gone to play football because taking care of the baby is a girl's work, your mother has left you with the child so they will say that this is for the boys and this is for the girls. There are still those gender roles.

Kibera Safe Spaces mentor respondent, age 21, VEHW

Further, some adolescents and one parent in Kibera said having to attend school classes on weekends kept girls from attending meetings. A few adolescents also reported that they came late or missed meetings because they were attending church. Similarly, in Wajir, one girl said that she had missed a meeting because she had to go to a Duksi class. Several parents in Wajir also reported a dissatisfaction with the meeting schedule since it interfered with religious teachings and one parent even said that their daughter was usually unable to attend Safe Spaces meetings because they interfered with Madrasa classes and recommended that the meetings be rescheduled to Thursdays or Fridays, as most girls do not have Madrasa classes on these days. One parent in Kibera also recommended rescheduling meetings from Sundays to Saturdays so that meetings do not conflict with religious services.

I have a question though you know that most of us do not attend AGI-K, especially the ones from this school because we come to school on Sunday at $2 \mathrm{pm}$ and we were told that if you don't attend the classes your fee will not be paid and the kit also you will not receive so I was asking what will we do now? Because you are needed in school and you are also needed to go for meetings.

Kibera adolescent respondent, age 14, VEH

We were told to go to school ... because like last term I went only for three Saturdays the rest of the days I went to school because when you miss going to school on Saturday, you are caned at school.

Kibera adolescent respondent, age 12, VEH

She normally does not attend them because she goes to Madrasa at 2pm, the time when these meetings are held, except on Fridays when there is no Madrasa [Islamic school]. Other days like Saturdays and Sundays she cannot attend them as she goes to Madrasa. The Madrasa teacher will punish her if she misses her classes.

Wajir parent respondent, female, age 39, VEHW

In addition to the barriers described by adolescents and parents, a few Safe Spaces mentors from both sites added that a lack of parent support or encouragement keeps girls out of meetings. For example, some mentors said that if a parent does not receive the household cash transfer or the child is not given their schooling kit then the child will not attend the meeting. In Wajir, mentors also reported that some parents were not supportive of their daughter's participation in the meetings because of a general lack of understanding of the AGI-K program and Safe Spaces curriculum. Thus, some mentors recommended continued sensitization of parents about the details and importance of the program and Safe Spaces meetings and curriculum, while others recommended that program staff remit the cash transfer payments on time to prevent adolescents from being kept from attending meetings. 
There are those whom if she comes today, tomorrow she don't come, they are not consistent. There are those who go to school up to Sunday or that Saturday, she can't be available to come for Safe Space. There are those whom, if the mother's money does not reach, she will never come for Safe Space. There are those whom, even if the money has reached and school fee has been paid but she didn't get sanitary pads, she won't come to Safe Space.

Kibera Safe Spaces mentor respondent, age 24, VEH

The other one is that the parent was told they will get 1,500 KES as cash transfer, and some refused their daughter to come to Safe Space because they told us, "You and the organization are collaborating; you are thieves, we only received money one term, since then we did not receive." The girls are willing to go and attend the meetings but they fear their parents and we can't fight them.

Wajir Safe Spaces mentor respondent, age 25, VEH

Respondent 1: During the Safe Space meetings you only see 7 girls or 5 girls attending, because the parent send them to look for firewood or even tell the girl to go to the kitchen and cook and the parents will tell their daughters that the teacher is not more important than me. [age 20]

Respondent 2: The parent is suspicious about the program because they say we know there is school and Duksi but what is this that is in between that this program is conducting? [age 30]

Respondent 3: The parent is asking the reason why girls at the age of adolescent (11-14 years) are chosen and not the 16-year-old girls or boys of the same ages. They say we see this as misleading. This therefore is a challenge. [age 24]

Wajir Safe Spaces mentors group discussion, VEH

\section{Experience as a Space Spaces Mentor}

Most mentors expressed an appreciation for the opportunity to mentor and advise the girls enrolled in Safe Spaces, share information with other girls and women in their communities, and also noted the positive effect that mentoring has had on their lives. For example, one mentor in Kibera discussed how involvement in this program is encouraging mentors to act as role models within their communities, while a mentor in Wajir explained how the Safe Spaces curriculum has better equipped her to protect her own daughter against early marriage.

Respondent 1: My experience is that before, these communities used to value and practice early marriage. You will find a 13-year-old girl married and no one was reporting, but now since this program started even the parents have the fear if they get their daughter married they will be reported. And as a mentor that is my responsibility if I see them practicing I will report them in order to protect the child, also I never had the confidence to speaking to people but now I can address the girls. [age 18]

Respondent 2: When I become a mentor I got the sense of being trusted by the community to teach their girls and also what I like from being mentor is that I got the opportunity to learn more about child spacing, FGM issues and child marriage which will be of great help to my family as well. [age 24]

Wajir Safe Spaces mentors group discussion, VEH

So, at times you yourself even fear because you have to act as a role model to the girls. Because maybe sometimes you tell the children, "Don't walk in darkness, you should not be seen with boys," and then a child finds you doing such things in Kibera. So it is building us mentors to act as a role model to the kids.

Kibera Safe Spaces mentor respondent, age 21, VEH

Other mentors in Wajir talked about the positive effect the program has had on their own self-esteem, confidence, and communication skills. Mentors from both project sites also discussed girls' increased willingness to share their problems with mentors and expressed satisfaction in their ability to provide girls with assistance and help 
them navigate the problems they encounter. However, mentors in Kibera also described the need for additional training on guidance and counseling skills since often girls and even their parents come to them seeking assistance to resolve conflicts and they do not always feel equipped to handle such situations.

Like in my class, there is a girl who got pregnant when she joined Form One but she was unable to tell her parents because she feared them, but she came and told me. I looked for a way and talked to her parents until they calmed down. The parents were very harsh but I just talked to them and we even went with her to her school and the teachers also agreed and said there is no problem and that when her time to deliver comes they would give her time to go and give birth then come back to school.

Kibera Safe Spaces mentor respondent, age 26, VEH

Respondent 1: Before I never had the confidence to stand in front of people but now I gained so much confidence that I can facilitate the session without any fear. The other one is child spacing, am now knowledgeable enough about topics like child spacing, FGM, and abstinence. [age 25]

Respondent 2: Even me I never had the confidence of speaking in public. There is a time I was called to teach in a school and I refused because I had no confidence to stand in front of the students. [age 22]

Wajir Safe Spaces mentors group discussion, VEH

And also, these girls, we have found that some of them are exposed. So there are things that even if we tell them in Safe Spaces, they know because they have already done them...So at least there should be those basic counseling skills and we will know how to handle them.

Kibera Safe Spaces mentor respondent, age 24, VEH

Several mentors in Wajir reported difficulty teaching some of the sexual and reproductive health topics. For example, some of the mentors in Wajir described parent push-back when trying to discuss FGM/C, and another mentor said that some girls do not want to learn about family planning because they fear it will lead to problems in their marriages. In addition, a couple of mentors in Kibera explained that exposing young girls to the sexual and reproductive health topics had actually caused some to experiment sexually when they previously would not have. Others added that the sexual and reproductive health topics may not be appropriate for girls aged 11 or 12 years and said that some parents get angry after learning that their young daughters have learned about sex. As a result, some of the mentors recommended excluding some of the sexual and reproductive health topics from the curriculum for that age group.

Respondent 1: When we talk to them about FGM their parents have the perception that these programs want to make their daughters non-Muslims. [age 33]

Respondent 2: When we talk to them about child spacing especially the married girls, they believe that it will bring negative effects to their family... Like it might cause a divorce if the girl talks to her husband on issue of child spacing, like using the family planning, because the husband might say the reason why I married you is to give birth to many children, if you want to do child spacing I will divorce you. [age 24]

Wajir Safe Spaces mentors group discussion, VEH

As for me as I said before am dealing with from 11 to 12 years and the topics that are relating to sex I'm actually having a very big challenge to teach these girls because they tend to coil and no one wants to talk, so you just talk but they are not opening up so that one has become a challenge... The change that I would recommend is that from 11 years they should be exempted from that curriculum, as in we should start teaching about sex from 12 to 14, but some of them are just too young ... for this they go home and tell their parents that they have been taught about strategies of delaying sex and then you have to explain to the parents why we are teaching them that and they feel bad, some of them feel bad.

Kibera Safe Spaces mentor respondent, age 30, VEHW 
Additionally, a number of mentors from both project sites discussed dissatisfaction with the stipend being received. In Wajir, mentors disliked that the stipend was conditioned on sending data, reporting that it can be difficult to get to the Save the Children offices to submit the data and they often lack money for transportation. They also described difficulty affording transportation to and from the villages where they conduct the Safe Spaces meetings since many are mentors in different villages from the one in which they reside.

Respondent 1: What I did not like is the payment. I'm a resident of [village] and where I mentor is [village] and there is no car to travel with and I must attend my Safe Space, so I take a donkey cart to reach the village of which I pay 1,000 KES to go and [come] back, even though I am helping my community I did not like the payment. [age 33]

Respondent 2: I also travel from [town] to [village] and sometimes when I don't have transport it's difficult for me to reach the village, or even sometimes when it rains and there is no car going they will charge me 1,000 KES and the money we are given is very little. [24]

Wajir Safe Spaces mentors group discussion, VEH

In Kibera, mentors noted not having enough money to make their follow-up calls or visits when girls missed meetings or having to use their own money to feed the girls who complained of hunger. Others explained how time intensive it is to be a mentor, especially when they have to make home visits or have also been put in charge of going to the schools to monitor the biometric measurements. As a result of these issues, mentors from both sites suggested increasing the amount of their stipend to cover some of the additional costs associated with being a mentor, and one mentor in Wajir requested that Save the Children staff come to them to collect attendance data. In addition, a few of the mentors from both Kibera and Wajir reported experiencing difficulty in handling girls who are not enrolled in the program yet still try to participate in the Safe Spaces meetings. As a result, one mentor requested permission to enroll girls into the Safe Spaces meetings even if they are not enrolled in AGI-K.

Respondent 1: The issue of airtime, some of us have girls, like 40 girls and we are all given the same airtime, so doing follow up with this $200 \mathrm{KES}$, like you cannot call like 40 parents, not even 10 parents with these $200 \mathrm{KES}$ so if maybe you could revise it we could be given more airtime and consider those people with lots of girls so that we are able to work with them effectively. [age 30]

Respondent 2: Let me add something, I like her passion, [name] goes for home visits frequently and we are not paid for home visits we are just given the 1,000 KES but us we go an extra mile for the home visits which are not paid for. They should also know how to motivate us. [age 21]

Kibera Safe Spaces mentors group discussion, VEHW

They call you to tell you that "teacher I haven't eaten since morning," so you are wondering how they are going to sleep without food in the evening. So I did not even know what to do ... I told the girl that we meet up at Olympic, and then I gave her 100 KES. Then there are some who come to Safe Spaces and tell you that I haven't eaten since yesterday. So you will have to get into your pockets a list if you buy them each one samosa they eat so that the class can go on; they can't be attentive because they haven't eaten since yester night.

Kibera Safe Spaces mentor respondent, age 25, VEHW

As mentors we were instructed we can't add anything, neither can we subtract anything, and during the Safe Space meetings those girls who are not in the program also come and request us to add them to the list of the Safe Space girls, and we have no power to do that. For these reasons we are requesting to be given that privilege/permission to add these girls to the program.

Wajir Safe Spaces mentor respondent, age 24, VEH 


\section{VIOLENCE PREVENTION THROUGH COMMUNITY CONVERSATIONS}

\section{Summary of Key Violence Prevention Findings}

At the time of data collection, the Community Conversations (CC) groups had been successfully formed in Wajir but were not yet active. As a result, information on the progression of CC meetings could only be obtained from Kibera respondents.

In general, CC facilitators noted satisfaction with the meetings and commented on their perception that their roles as CC facilitators had already had a positive effect on them as individuals. In their role as facilitators, they have been empowered to become strong leaders and role models within their communities, evidenced by how community members seek their help and guidance in solving problems and resolving personal conflicts. Although facilitators and committee members discussed several areas of satisfaction with the progression of meetings, they also discussed reasons why community members may not attend meetings, including poor communication about meeting details, and they expressed concern about the attendees being only those who are directly benefiting from the program.

\section{Satisfaction with CC Meetings and Effect on Community}

Facilitators in Kibera expressed their satisfaction with the Community Conversations (CC) meetings, explaining that they have helped improve the community by bringing people together, helped reduce tribalism, and have created a

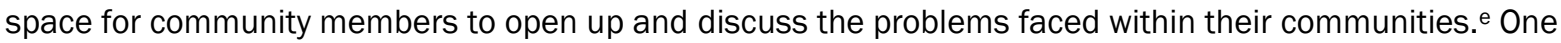
facilitator also mentioned that, from these meetings, some community members have gone on to form other community-based organizations. Some of the CC committee members in Kibera also stated that the meetings were providing an opportunity for parents to discuss the difficulties experienced by their children and to come up with potential solutions, while another CC member described how the meetings are used as a forum to educate the community on gender equality and to communicate and resolve cases of community violence, such as occurrences of rape. In addition, CC facilitators and committee members also believed that the meetings would result in continued improvements in girls' school enrollment and their overall well-being as the importance of education is a central theme at meetings.

Okay, another thing I have seen is that you find that a parent had issues with her child but now that they (parents) are together you find that even her fellow parent has the same problem as hers, so they share. But because they were kept silent, you will find that another parent has the same problem as hers, so they open up, talk, and find ways of helping themselves.

Kibera CC facilitator respondent, female, age 45

Especially the parents who come to those community conversations have ended up forming communitybased organizations. While others wouldn't have known each other. So it has brought them together, though not all in the community have been captured. At least it has brought over 60 people together and formed a group that is like bringing unity in the community.

Kibera CC facilitator respondent, male, age 32

There are so many issues that take place. Issues like rape cases, gender violence, you find also social injustice they all take place here. So at least we are taught to tackle such issues, issues like rape like what I encountered the other day here at the stage, there was a girl who almost got raped by certain boys. So what we did... We went around and caught all the four guys, we didn't beat them. We wanted to show them that there is law and so we involved the police who came and arrested them and now justice is served.

Kibera gatekeeper respondent, male, age 20

\footnotetext{
e At the time of the qualitative data collection taking place, CC meetings were in the early stages of implementation
} in Wajir. As a result, only results from Kibera CC facilitators and committee members are included in this report. 


\section{Meeting Attendance and Participation}

CC facilitators and committee members reported a number of factors that may contribute to community members not attending meetings, including people being busy running their businesses, a lack of or poor communication about meeting details, and meetings conflicting with other activities, such as religious services or classes. Facilitators also explained that most of the attendees are beneficiaries of the program, noting the difficulty they have in promoting the meetings among other community members who themselves or their daughters are not directly benefiting from the project. In Kibera, one of the committee members also noted that most of the attendees are those who live nearby or who have been personally invited to attend. In order to promote attendance among community members, some of the facilitators and committee members recommended providing some sort of incentive to attendees, such as a small payment, and described the need to enhance awareness about the meetings and for timely communication of meeting details (e.g., meeting location and time).

Respondent 1: There is this problem that there are several NGOs in Kibera, people believe that they have to be paid to attend the meeting, so if you tell there is a favor then you will have a hard time controlling them, some though if they come they will be given something they started withdrawing that is the other challenge. So that is also a challenge. [male, age 35]

Respondent 2: If my child is not a beneficiary of the program, there is no need I sit in that community conversation meeting. [male, age 32]

Respondent 1: They assume those who go for the meetings are those whose children are paid for fees. Some say if my child is not paid for fees there is no need for the meeting.

Kibera CC facilitators group discussion

\section{Experience as a CC Facilitator}

In general, facilitators described their experience as positive, mentioning their pride and a sense of empowerment in leading the group and how it brought community members from differing backgrounds together to collectively solve problems in their community. One facilitator even discussed how meetings have helped to improve parentchild relationships in the home. Some facilitators also mentioned how members of the community now respect and trust them, often coming to them for help or guidance when they are experiencing problems.

Respondent 1: It has helped to bring the community together and to bring openness in the community. Previously you would find people living solitary lives. Households living by themselves, like it's just my relatives and $I$. But now it has brought the community together. Yes, it has brought unity and it has also helped in bringing openness between the parents and the recruited children. You find initially, that a child was not able to address or discuss issues with their parent but now there is openness. You find that in the house, when there is openness there is harmony of the community. The gap that was there between parents and children is ended. [male, age 70]

Respondent 2: Okay, the experience I have encountered is ... in fact I have become very proud because the respect between the community and I. It has become more, because now as you know I am a community leader and I always have so many activities with them so I came to be a facilitator it gave me more respect. You find people come to ask me about the girl child, they also bring some cases... So the community has empowered me more. [female, age 45]

Kibera CC facilitators group discussion

While facilitators' views about the community conversations were positive, they acknowledged several challenges. Similar to the Safe Spaces mentors, facilitators described a need for additional training in guidance and counseling, as well as conflict resolution so they would be better prepared to handle certain situations that arise among community members, such as domestic disputes. Some of the facilitators also requested greater compensation, underscoring the amount of work that is involved in the role and the need to occasionally use their own money to assist other community members.

Respondent 1: Sometimes you are asked to mobilize people, you have to call. You get $200 \mathrm{KES}$, you call maybe around 20 people and that's it finished. You are left with nothing, forcing you to use your own money from the pocket. [male, age 35] 
Respondent 2: Okay, there are these problems in the house, people quarrel and then she comes to you so that you can go and talk to the husband. So it looks like you are the one who solves their domestic problems. Because they see you as the facilitator at the community conversation and because you teach them, they feel you know everything. [male, age 32]

Kibera CC facilitators group discussion

I see this work of facilitating goes hand in hand with guidance and counseling. For where there is a problem is where we are called to counsel. If it is something that can be added to us, this skill of guidance and counseling children and parents whenever they will have a problem.

Kibera CC facilitator respondent, female, age 30 


\title{
Key Findings and Implications
}

\section{EDUCATION SUPPORT PROGRAM}

\author{
Household Cash Transfer (HCT) and School Fees
}

Most program beneficiaries highlighted the benefits of having school fees paid and receiving the household cash transfer (HCT), including improvements in school attendance and having more money available for other household needs. Parents also noted improvements in their child's self-esteem and communication skills. It is hypothesized that by receiving the HCT and partially removing the burden of school fees, the negative stigma of girls being chased away from school is removed, thus improving confidence in the classroom.

Although many beneficiaries reported satisfaction with the HCT and had no issues with payment, several said that they received their HCT late or were unable to access their payment altogether. In Wajir, especially, the reasons why some might have had difficulty opening their accounts or accessing their payments were external to the program. These reasons included not having the proper identification or the distance from the nearest bank. Both implementing partners continue to work with beneficiaries to mitigate these challenges as best they can. In addition, Save the Children staff are working to ensure that households in Wajir know where they can access the cash transfer. Specifically, they should be made aware that the study design included the availability of a local Equity Bank agent near each study village, removing the need to travel all the way to Wajir to access the money from their account.

Despite repeated community sensitization efforts in both project locations, misconceptions about the educationsupport program remain. It is important that beneficiaries understand that the program only pays a fraction of the girls' total school fees and that parents may still have to make additional payments. Thus, in both Kibera and Wajir, implementing partners are working with schools and Safe Spaces mentors to ensure that parents and adolescents are better informed about what is being provided by AGI-K and what is not, in terms of school fees. There will also be continued sensitization of parents, adolescents, and school heads and teachers on the timing of school fees and HCT payments. In particular, parents and the school management will be informed that payments can only be made after verification of girls' enrollment and attendance status. Project staff will work to expedite the verification of school enrollment and attendance so that both school fees and HCTs can be remitted without delay. Additionally, project staff and implementing partners will work with schools to come to an agreement on the timing of when schools can expect fees to be paid, preventing girls from being mistakenly sent away.

In Wajir, the findings also highlight the potential for misconceptions about the true intentions of the AGI-K program, including rumors that the HCT was being given in exchange for girls being sent away to another country. As a result, Save the Children staff continue to sensitize both the wider community and program beneficiaries about the study, its purpose, and why some are receiving certain benefits. Furthermore, because of the concerns raised about disparities between girls who are enrolled in the program and those who are not, both implementing partners will continue to sensitize the wider community, including mentors, teachers, parents, local administration and adolescents, about the research design and the randomization of participants. It will also be important for implementing partners to work with school administrators and teachers to ensure that girls who are enrolled in the program are not singled out or given differential treatment, to reduce sentiments of unfairness.

\section{Schooling Kit}

Overall, study findings demonstrate satisfaction with the items being provided in the schooling kits and show that the items are being used as intended. Although some parents and adolescents reported dissatisfaction with the sizing of the underwear, the sizing has been adjusted and it is now expected that fewer girls will report problems.

\section{Biometric Measurements}

In general, the process evaluation findings highlight a myriad of challenges associated with the daily biometrics. The disruption it causes in lessons has implications for both participating and nonparticipating girls. Certain changes to the process of capturing attendance using the biometrics system have already been implemented since completion of qualitative data collection, including the provision of more devices to schools that have a large number of girls enrolled in the program. In addition, implementing partners are conducting random spot checks as well as follow-up with school heads and teachers to ascertain whether the process has improved and provide further assistance to those still experiencing challenges. For schools that continue to face difficulties with the daily 
biometric data collection, attendance data will be collected on random days by external research assistants for the duration of the study.

\section{School Monetary Incentive}

Study findings highlight the perceived positive effect that the monetary incentive has had on school development, allowing schools to repair classrooms, purchase supplies, and even hire additional support staff. Despite the general satisfaction with the monetary incentive being provided, some reported a dissatisfaction with teachers responsible for administering the daily biometric not being adequately compensated. The program allowed schools the freedom to choose how they use the monetary incentive, as different schools have different needs. However, during meetings with school heads and teachers, implementing partners can discuss the importance of compensating teachers to ensure data quality.

\section{SAFE SPACES}

Qualitative findings highlight the noticeable perceived effect of the Safe Spaces meetings on the girls from both the parent perspective and the perspective of the girls themselves. In Wajir, the results provide early indications of changes in attitudes toward early marriage, an important pathway to delayed childbearing in the AGI-K Theory of Change. In Kibera, findings indicate increased social assets, such as aspiration and self-esteem, also outlined by the AGI-K Theory of Change.

One of the objectives of the Safe Spaces model is to improve adolescent well-being via the establishment of strong social networks. Adolescents from both Kibera and Wajir reported that they had formed positive relationships and friendships with the other girls in their Safe Spaces group, thus expanding their peer networks. Girls also said they shared what they had learned in their meetings with other friends and family members. As much as this may raise concern for potential contamination between girls randomized to the VEH or VEHW arms and those randomized to the V-only or VE arms, the potential positive effect that information sharing can have on other girls not enrolled in the program cannot be ignored. This will be taken into consideration and adjusted for in the impact evaluation, ensuring that the potential for contamination is appropriately measured during the midline and endline surveys.

The study results also highlighted some important differences in the views of girls and parents on missing meetings and the perceived effect of the Safe Spaces meetings. The girls' views were more positive and many reported that they missed meetings mainly because of other responsibilities, such as domestic chores, or because they had to attend school or participate in religious activities. Particularly in Wajir, both parents and gatekeepers also expressed their concerns with the scheduling of meetings and their interference with attending religious classes. Additionally, findings from the interviews with parents and gatekeepers in Wajir also highlight concerns about the content and purpose of the Safe Spaces curriculum. Implementing partners will therefore discuss the scheduling of the meetings with parents and gatekeepers and make necessary changes. Further, continued community sensitization about the purpose of the Safe Spaces groups and the importance of the topics to girls' well-being is warranted. It is expected that once improvements are made to the HCT and school fee components, this will result in fewer parents discouraging their daughters from attending the meetings, a concern raised by Safe Spaces mentors.

Qualitative findings also highlight the perceived positive effect the program has had on the mentors themselves, as their roles have increased their own knowledge, self-esteem, confidence, and capacity. The results provide evidence of the progress made among mentors in Wajir, where great difficulty in appointing qualified mentors had been experienced. In both project sites, mentors have been able to forge important relationships, as they described both girls and their parents coming to them seeking help when experiencing problems. To ensure that facilitators feel comfortable in their capacity to handle such cases, additional training will be provided to encourage the development of necessary counseling skills. Additionally, project staff will make certain that mentors are aware of the different services available within their communities where girls and parents can be referred for additional support.

\section{Curriculum}

Although parents and gatekeepers in Wajir reported satisfaction with many components of the curriculum, such as topics related to menstrual hygiene and management and savings, the research findings also highlight the many misconceptions and concerns that still exist surrounding some of the topics covered in the sexual and reproductive health curriculum. While it is recognized that many of these misconceptions may be driven by certain religious and cultural norms in the community, sensitization around study and program objectives and the Safe 
Spaces curriculum will continue in order to improve participation and uptake and reduce parent and gatekeeper push-back.

In Kibera, parents and adolescents described a general satisfaction with the knowledge being gained from the topics covered within the sexual and reproductive health curriculum. However, qualitative results also highlighted concern among some mentors about providing sexual and reproductive health education to girls aged 11 or 12 , as they believed it led to increased curiosity and promiscuity and earlier sexual initiation. It is important to keep in mind that previous research does not support this notion. Research has shown that comprehensive sexuality education (CSE) is associated with delayed sexual initiation among young people, decreased rates of STIs, and increased knowledge about the consequences of risky sexual behavior. ${ }^{9-11}$ Nevertheless, to ensure that the curriculum is being delivered appropriately, additional training with mentors has already taken place since the completion of the qualitative interviews, during which the curriculum was reviewed in detail and mentors were provided feedback on how to best deliver curriculum content. Implementing partners from both project sites will take special care in continuing to monitor meetings closely, being especially cognizant of content delivery and understanding.

\section{COMMUNITY CONVERSATIONS (CC)}

At the time of data collection, the CC groups had been formed in Wajir but were in the early stages of the dialogue process. As a result, information on the progression of CC meetings could only be obtained from Kibera respondents. In general, findings from the qualitative results highlight the perceived positive effect that the CC meetings have already had on the Kibera facilitators themselves. Their role as CC facilitators has empowered them to become strong leaders and role models within their communities, evidenced by how community members sought their guidance and assistance in solving problems or resolving conflicts. To ensure that facilitators feel comfortable and confident in their capacity to handle such issues, additional training on guidance and counseling and conflict resolution will be provided. Additionally, facilitators will be made aware of other avenues of support available to community members so that they can make the proper referrals.

Facilitators discussed several reasons why community members may not attend meetings, including poor communication about meeting details, and also expressed concern over regular attendees being those who are directly benefiting from the project. Going forward, both implementing partners will work with the CC facilitators in devising strategies for improving attendance and improved communication regarding meetings details, such as meeting dates, times, and locations. Implementing partners will also closely monitor CC meeting membership, as the intention is for meetings to encompass a cross-section of the community, not only beneficiaries of the project. 


\section{Conclusion}

The findings from the first round of qualitative data collection have provided important information about the perceived effects of the program from a diverse set of respondents. Overall, beneficiaries, their parents/guardians and other key stakeholders value the program and have observed positive changes in girls' education, knowledge, self-esteem, and money management. In addition, the findings have revealed key areas for improvement within each intervention sector. In the second year of implementation, teams will focus on addressing these issues. 


\section{Appendix A}

\section{AGI-K NATIONAL EXTERNAL ADVISORY COMMITTEE}

1. Kenya Women Parliamentary Association (KEWOPA)

2. National Gender and Equality Commission

3. Gender Directorate, Ministry of Devolution and Planning

4. Department of Children's Services, Ministry of Labor, Social Security \& Services

5. Department of Policy, Partnership and EAC, Ministry of Education

6. Division of Reproductive Health, Ministry of Health

7. Department of Health, Wajir County

8. County Department/Sector of Education, Wajir County

9. Kadhi, Judicial Service Commission, Wajir County

10. Wajir County Government, Humanitarian Coordinator

11. Kenya Post Office Savings Bank (Postbank)

12. Equity Bank/Equity Group Foundation

13. Gender and Social Development, Kenya Private Sector Alliance

14. Footprints Africa Foundation

15. UNICEF Kenya

16. UN Women

17. UNFPA, Reproductive Health and Youth

18. UNESCO

19. ALDEF - Wajir Local NGO

20. WASDA - Wajir Local NGO

21. Center for Rights Education and Awareness (CREAW)

22. Girl Child Network

23. Center for the Study of Adolescence (CSA)

24. Association of Media Women in Kenya

25. Department of Community Health, University of Nairobi

\section{AGI-K KIBERA EXTERNAL ADVISORY COMMITTEE}

Office of the MP, Kibra Constituency

2. Nairobi County Assembly

3. Department of Children's Services, District Children's Officer

4. Deputy Gender Officer - Kibera, Langata Subcounty

5. County Education Officer, Nairobi County

6. District Education Officer, Langata Subcounty

7. Public Health Officer, Langata Subcounty

8. District Health Officer, Langata Subcounty

9. Assistant District Health Officer, Langata Subcounty

10. District Commissioner, National Administration

11. Equity Bank, Kibera Branch

12. Post Bank, Kenyatta Market Branch

13. Kenya Primary School Heads Association - Langata Constituency

14. Kibera Paralegal Network

15. Carolina for Kibera

16. Undugu Society

17. Shining Hope for Communities Lea Toto

18. Kibera Informal Settlements Association

19. SAVO Foundation CBO

20. Global Communities

21. Umande Trust

22. Concern Worldwide

23. DARAJA

24. African Network for the Prevention and Protection against Child Abuse and Neglect

25. Centre for Rights Education and Awareness

\section{AGI-K WAJIR EXTERNAL ADVISORY COMMITTEE}

1. Department of Children's Services, Wajir County

2. Wajir County Government, Humanitarian Coordinator

3. County Director of Education, Wajir County

4. County Health Director, Wajir County

5. County Reproductive Health Coordinator, Wajir County 
6. National Drought Management Authority, Hunger Safety Net Program, Secretariat

7. Gender and Social Services, Wajir County

8. Chairman, Court User Committee, Judicial Service Commission, Wajir County

9. Teachers Service Commission, County Director

10. Community Strategy Focal Point, Wajir County, Ministry of Health

11. County Executive Committee Member - Education, Wajir County

12. Equity Bank - Wajir Branch

13. Kenya Primary School Heads Association - Wajir

14. Kadhi, Judicial Service Commission, Wajir County

15. Council of Imam Preachers of Kenya

16. Supreme Council of Kenya Muslims

17. Wajir Paralegal Network

18. Discovery Learning Alliance

19. OXFAM

20. Islamic Relief

21. WASDA

22. ALDEF

23. Mercy Corps

24. Human Rights Watch 


\section{Appendix B}

Causal Mechanisms by Which Interventions Might Affect Timing of Childbearing

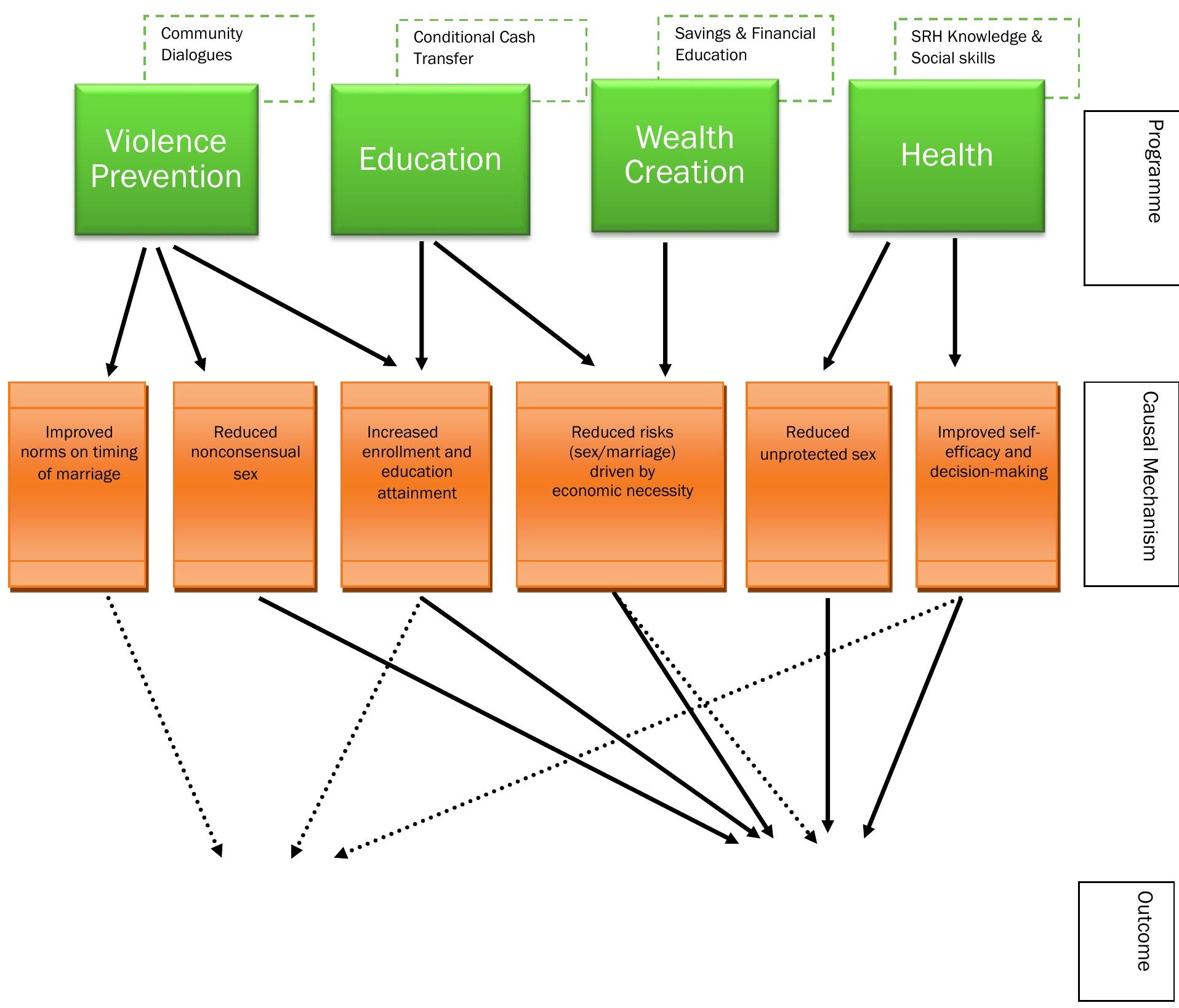

Legend $\quad \cdots \cdots \rightarrow$ Causal pathway in Wajir

$\longrightarrow$ Causal pathway in Kibera 


\section{References}

1. Kenya National Bureau of Statistics (KNBS). 2015. Kenya Demographic and Health Survey 2014. Calverton, Maryland: KNBS and ICF International.

2. Burt, M.R. 2002. "Reasons to invest in adolescents," Journal of Adolescent Health 31(6): 136-152.

3. African Population and Health Research Center. 2014. “Nairobi Cross Sectional Slum Survey (NCSS) II: Report on Demographic Behavior, Health Outcomes and Livelihoods Conditions of the Urban Poor in Nairobi Informal Settlements." Unpublished report. Nairobi: African Population and Health Research Center.

4. Kenya National Bureau of Statistics (KNBS). 2010. Kenya Demographic and Health Survey 2008-09. Calverton, Maryland: KNBS and ICF Macro.

5. Austrian, K., E. Muthengi, T. Riley, J. Mumah, C. Kabiru, and B. Abuya. 2015. "Adolescent Girls Initiative-Kenya Baseline Report." Nairobi: Population Council.

6. Austrian, K., E. Muthengi, J. Mumah, E. Soler-Hampejsek, C.W. Kabiru, B. Abuya, and J.A. Maluccio. 2016."The Adolescent Girls Initiative-Kenya (AGI-K): Study Protocol," BioMed Central Public Health 16(1): 1-14.

7. Austrian, K. and D.Ghati. 2010. Girl Centered Program Design: A Toolkit to Develop Strengthen \& Expand Adolescent Girls Programs. Nairobi: Population Council.

8. Bruce, J. and J. Sebstad. 2004. "Building assets for safe and productive lives: A report on a workshop on adolescent girls' livelihoods." Paper presented at Adolescent Girls Livelihoods Meeting.

9. UNESCO. International Technical Guidance on Sexuality Education, Volume 1. 2009. Paris: United Nations Educational, Scientific and Cultural Organization.

10. Haberland, N, and D. Rogow. 2015. "Sexuality Education: Emerging Trends in Evidence and Practice," Journal of Adolescent Health 56(1): 15-21.

11. Haberland, N. 2015. "A case for addressing gender and power in sexuality and HIV Education: A comprehensive review of evaluation studies," International Perspectives on Sexual and Reproductive Health 41(1): 31-42. 
Population Council General Accident House

Ralphe Bunche Road PO Box 17643-00500 Nairobi Kenya 